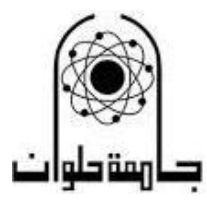

كلية الفنون التطبيقية

\title{
تأثير الفكر التأملي علي العملية الإبداعية للمصمم
}

Effect of Meditative Thought on The Creative Process of The Designer

\author{
إعــــــد اد \\ أستاذ. دكتهـور \\ محمد متولي عـامر \\ أستاذ تصميم المنســوجات المركبة \\ كلية الفنون التطبيقية

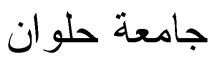

$5 r+12$ 


\section{تأثير الفكر التأملي علي العملية الإبداعية للمصمم \\ Effect of Meditative Thought on The Creative Process of The Designer}

$$
\text { ملخص البحث: }
$$

تتاولت الدراسة أهم التعريفات العلمية للفكر التأملي فلسفياً وعمليا، وكذا المنهج العلمي لإكساب وتتمية مهار ات التأمل و الملاحظة ، و انعكاس ذلك على تتمية القدرات الإبداعية، و التصميمية لاى المصمم؛ وذلك من خلال استعر اض بعض التصميمات الصناعية، و الأعمال الفنية التشكيلية المستمدة و المستوحاة من تأمل وملاحظة المصمم للظواهر الطبيعية ، و المنتجات التصميمية، و الفنية السابقة للوصول إلى الفكر التصميمي و التقني

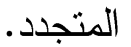

ثم استعر اض ما توصلت إليه الدراسة من نتائج التي تؤكد العلاقة بين مهارات التأمل و الملاحظة، و القدرات الإبداعية و الفكر المتجدد لدى المصمم أثناء العملية الإبداعية و عمليات الثقييم و الثقويم، و الاختيار بين البدائل، بما يحقق الإبتكارية في تصميم منتجاته

الكلمات المفتاحية : الفكر التأملي - مهار ات التأمل - العملية الإبداعية - مهار ات التصميم 


\begin{abstract}
:
The Paper has been studied the most important scientific definitions of contemplative thought philosophically and practically As well as to give the scientific method and the development of meditation and observation skills, and its impact on the development of creativity, design and the designer, through the review of some of the industrial designs, artwork plastic derived from and inspired hopes and Note designer of natural phenomena, and product design earlier access to technical design and technical thought renewed.

The study review results that confirm the relationship between meditation and observation skills that achieve innovative in its products
\end{abstract}

Key Words : Meditative Thought - Meditation Skills - Creative Process - Design Skills 
يعتبر تأمل المصمم في كل ما يحيط به من أثنياء، ومعاني، وأحداث، مسن أهـــ المفردات التكوينية للمصمم المبدع؛ و الذي من خلاله بستطيع تكوين رؤيثه تجــاه القضــايا التي يهتم بها، و التي يزيد عمقها بعمق ثقافته ودقة فكره التأملي. و التأمل في الطبيعة و النفس، وقضايا الاحتياجات الضرورية، و المعتقدات الدينية، و العادات

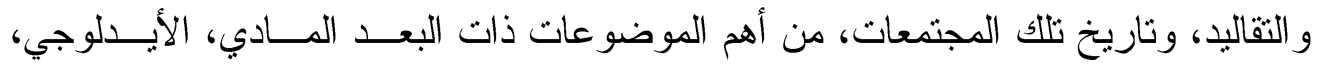
و الفلسفي؛ والذي يجب على المصمم تأمله بعمق شديد وفهم و اعي؛ باعتبار كل هذا من أهم الهم

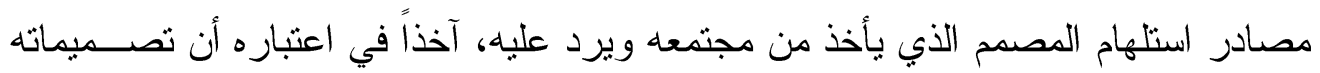

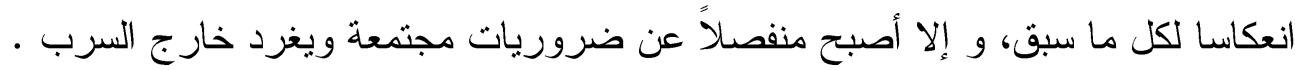

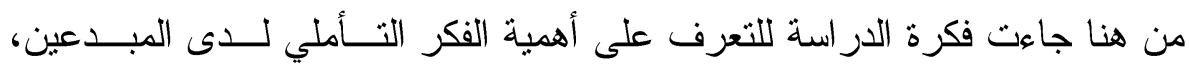

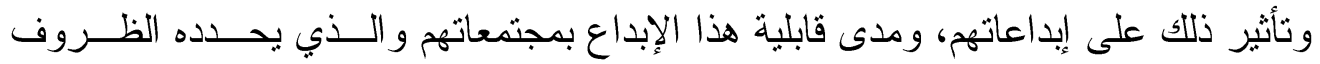

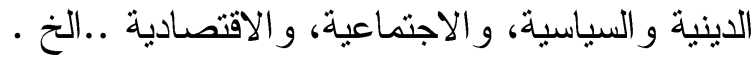
تزى الدر اسة أن ثقافة التأمل، من الممكن أن تكتسب وتصقل وتنطور من خــالهل

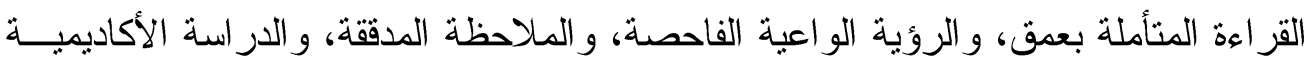

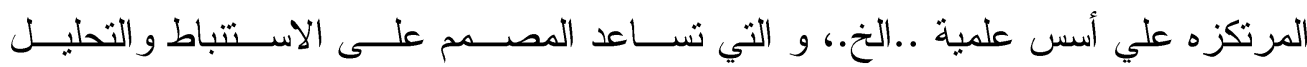
و التجريب المستمر ، ثم تقييم النتائج، باعتبار الفكر التأملي أحد المهارات الأساسـية التهي التي

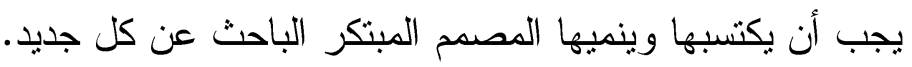

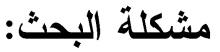

تبلورت مشكلة البحث من خلال الأسئلة الأثية : 1- هل يوجد علاقة بين علاقة طرديه بين زيادة الفكر الثأملي و الفكر الإبتكارى المتجـدد

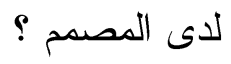
ץ- ما هى العلاقة بين مهار ات التأمل و العملية الإبداعية لدى المصدم؟

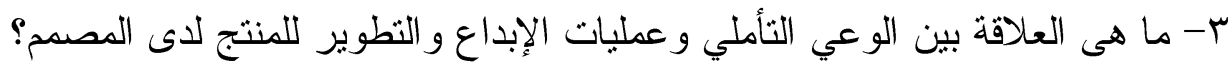

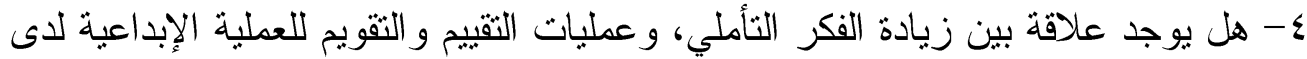


وبمحاولة الإجابة علي مثل هذه التساؤلات وغير ها لتوضيح تأثثر الفكر التأملي علي العملية

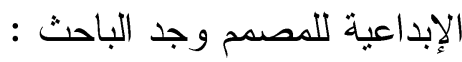
1- قلذة الدر اسات الأكاديمية المرتكزة علي أسس علمية لتوضيح العلاقة الوثيقة بين الفـــــر

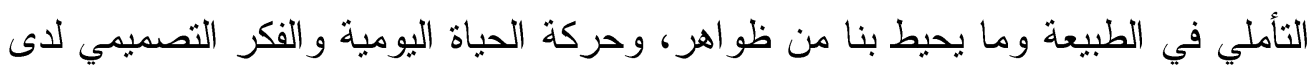
المصمم . r- قلة الدر اسات الأكاديمية القائمة علي منهج علمي مــرتبط بالبعــــ الفلسـفي لإكســاب مهار ات الثأمل للمصمم، و التدفق الفكري المتجدد في استتباط وتطوير أفكاره التصميمية ـ

\section{هدف الاراسة :}

1- التعرف على تأثير الفكر التأملي على العملية الإبداعية للمصمح .

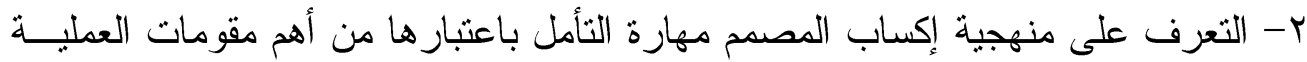
التصميمية . r- التأكيد على العلاقة بين سيكولوجيا التأمل و التصميم لاى المصمم و المستهلك.

\section{أهمية الار اسة :}

1- زيادة الوعي الفكري، و الفلسفي، و الإبداعي لدى المصدم و المستهلك. r- تأكيد العلاقة بين مهار ات التأمل لادي المصمم و المقومات الأساسية للعملية التصميمية .

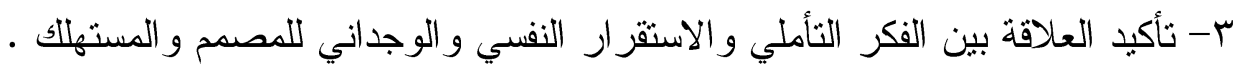

\section{فروض الدراسة :}

1- يوجد علاقة طردية بين زيادة الفكر التأملي و الفكر الإبتكارى المتجدد لدى المصدم.

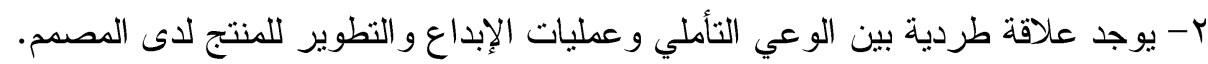

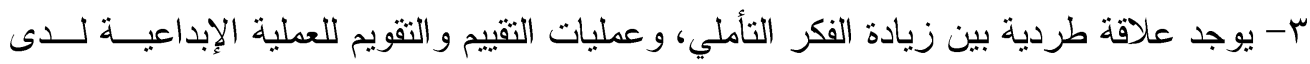
المصمم. ع - يوجد علاقة طردية بين زيادة الفكر التأملي وعمليات التقيبم والاختيار لدى المستهلك.

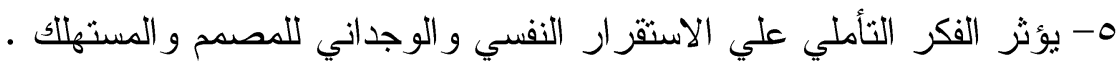




\section{منهجية البحث: - 2 - 20}

أتبع البحث المنهج الوصفي التحليلي لتوصيف التعريفات، وتقنيات العلمية لعمليات التأمل و الملاحظة ، وكذا العملية الإبداعية لاى المصمم ، ومدى العلاقة بينهما ؛ و المــنهج

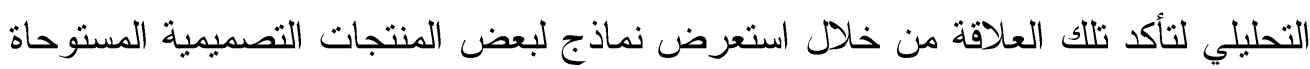
من خلال الفكر التأملي، و الملاحظة المدققة في تركيبــة الإنســان العضـــــية و النفســـية، و الظو اهر الطبيعة، و الكائنات المختلفة..الخ، و وكذا بكل ما يحبط بالمصمم من حر الك يومي.

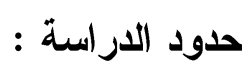

1- إلقاء الضوء على بعض التعريفات العلمية للتأمل و الملاحظة ، وكذا مهار ات اكتشــابها

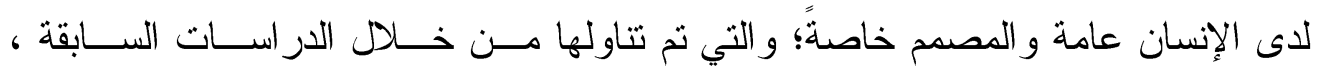

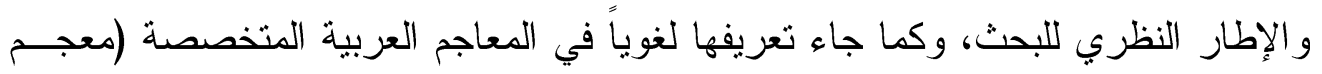

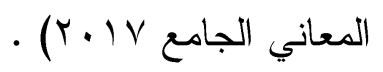
ب- توضيح العلاقة بين الفكر التأملي و استتباط المصمم لأفكاره التصــميمية مـنـ خــلاد

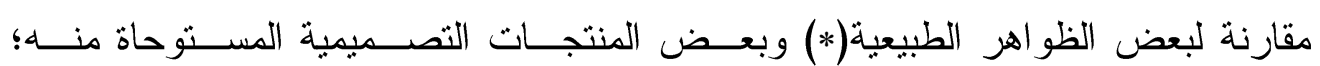
و الموضحة في مجموعة النماذج التصميمية المختارة لتوضيح فكرة البحث . 
الار اسات السابقة (Previous Studies): من الأمور الهامة المتعلقة بموضوع الدراسة ما يعرف بالفكر التأملي، ومهار ات التأمل، و

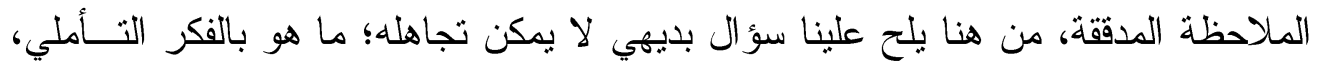

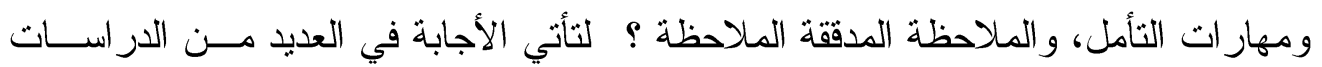
نتعرض لبعضها المتعلق بموضوع الدر اسه و التي يضيق بها المقام في ورقة بحثية.

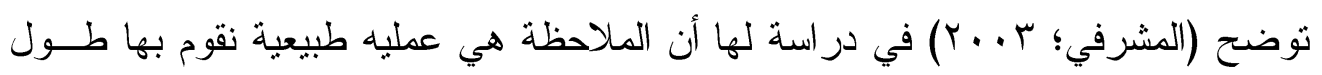

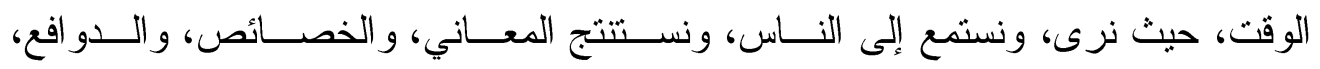
و الأحاسيس، و النوايا؛ و التأمل و الملاحة المدققه في الأشخاص على سلي سبيل المثال تشعرنا ما

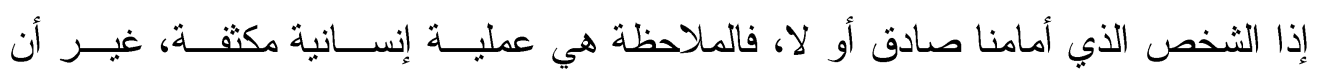

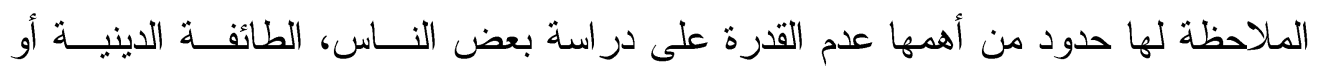

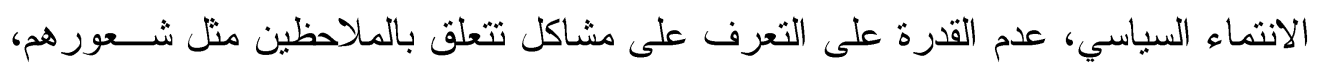

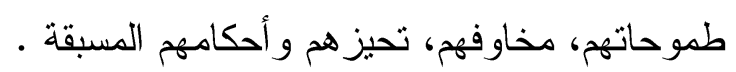
وفي در اسة لكل من : (Walter.W., Mills. Md., \& John. T. Farrow ; 1981) National Council for Curriculum and ) بمدينة دبلـن بأيـرلندا (NCCA)

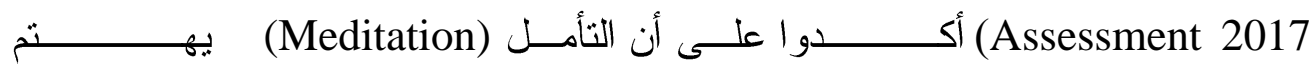

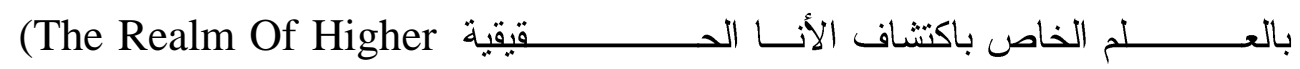
بالع Self)

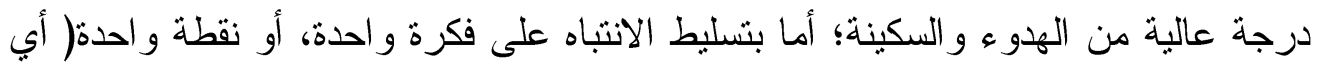

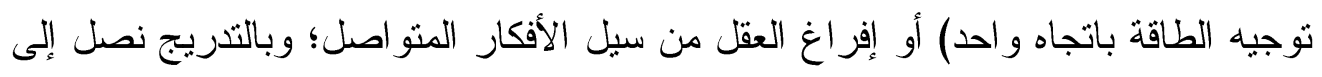

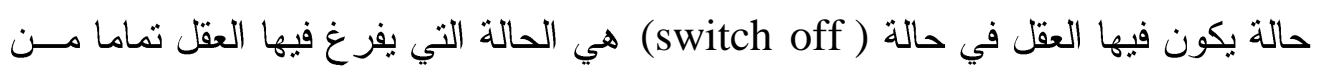

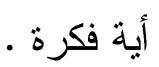
وقد تتاول بالدر اسة والتحليل تسلسل عمليات التأمل الو اعي، وكيفية التنريب عليها كل من (Hodgins, H. S., \& Adair, K. C, 2010 : Pp 872-878)

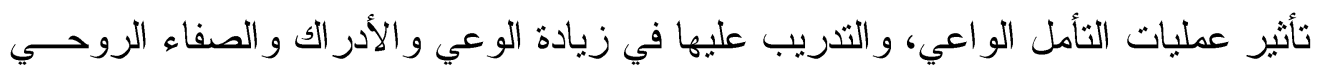

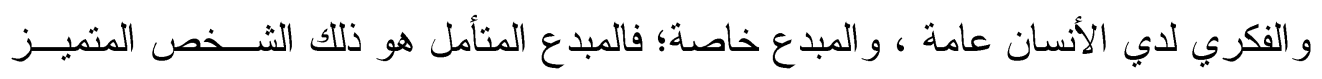

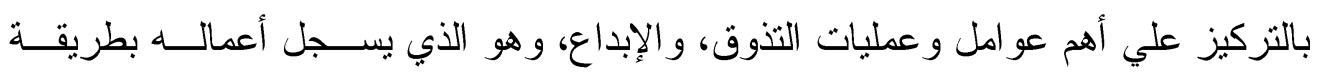


مباشرة و سريعة؛ وهو الثخص الذي يحفر فكره طبقة ور اء طبقه، أب أعمق فأعمق، حيث

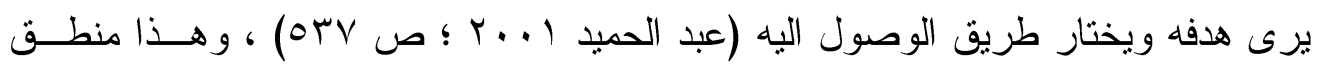

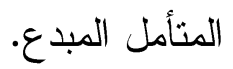

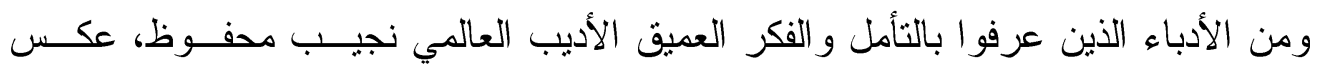

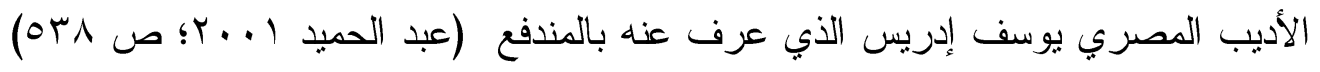

و الاندفاع و التأمل هنا لا يتعلقان بصفتين تقيم إحداهما سلبية (الاندفاع)، و الأخرى إيجابيــة

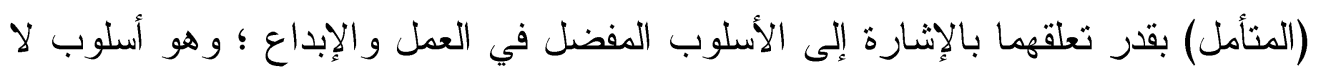

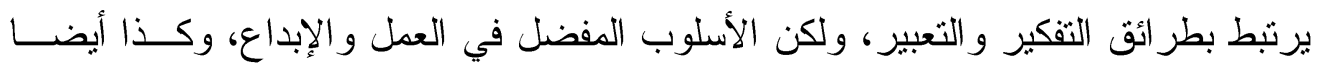

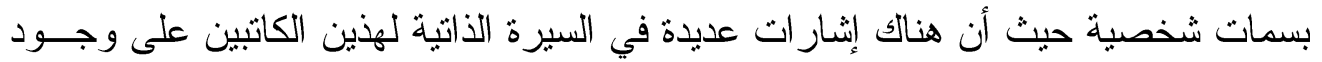

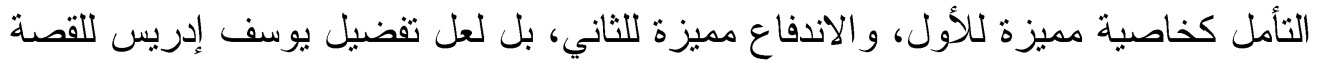

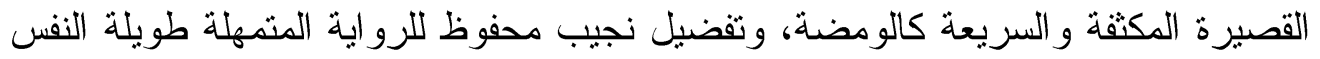

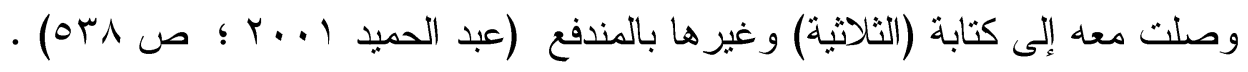
فالتأمل لدى المبدع (المصمم) أسلوب معرفي يرتبط بالإزجاء، و الانتظار ، و الصبر ، و والدقة.

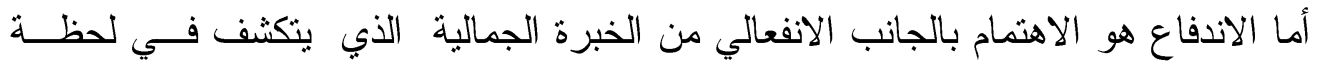

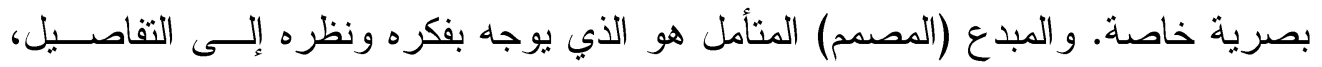

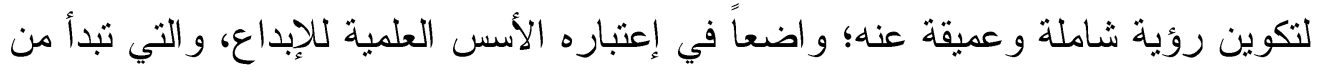

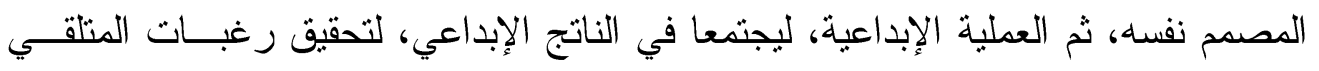

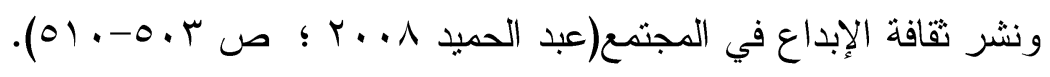
يجب علي المبدع ( فنان، مصمم، باحث...الخ من التخصصات المختلفة) أن يتميز بــالفكر

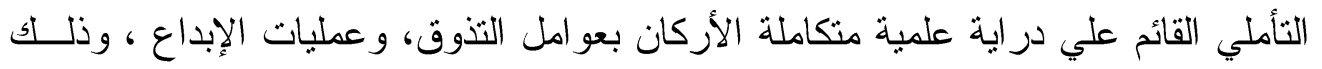

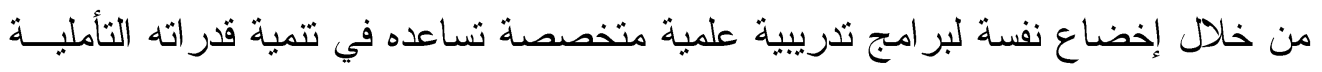

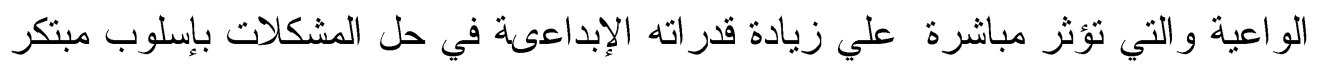

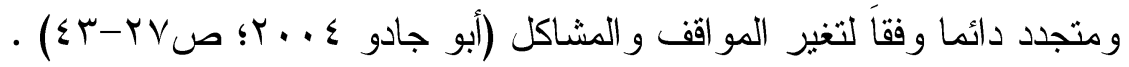




\section{لذا وجب علينا الإجابة على ما يلي:}

1- كيف تتمى قدرات الإنسان على الملاحظة و التأمل، وبالأحرى المبدعين ومنهم بطبيعــة

الحال الفنان المصمج؟

r- ما هي المنافع التي تعود على الإنسان و المبدع شديد الملاحظة و التأمل ؟

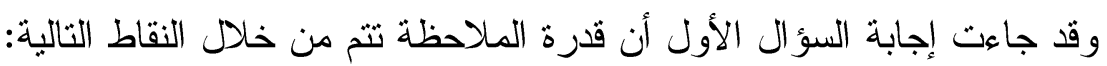

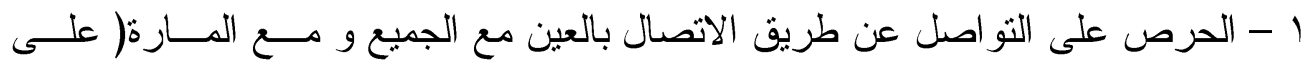

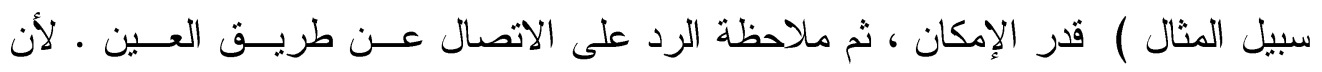

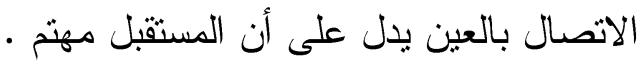

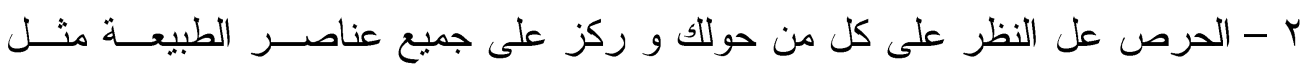

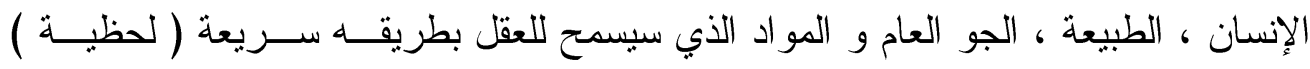

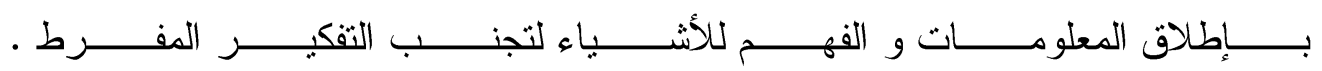
r - سجل الظو اهر الغير طبيعية، و المشكك فيها، وتصرفات الناس، وحركــات وضـــيج الأشياء.

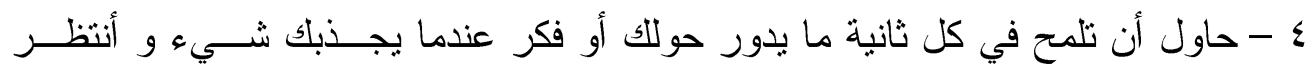

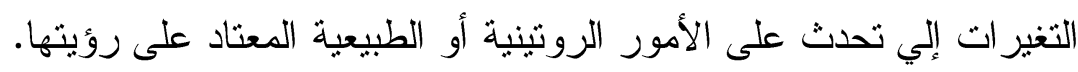

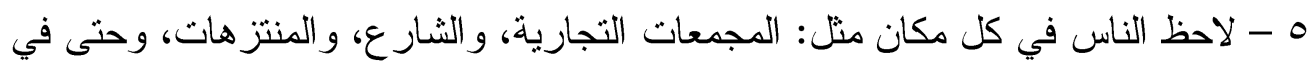

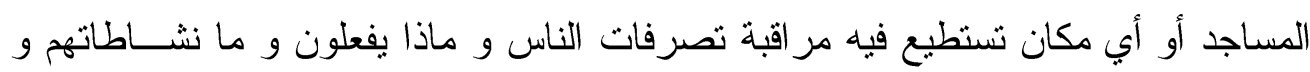
كيف يتعاملون مع حياتهم اليومية

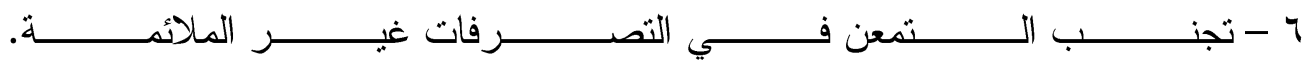

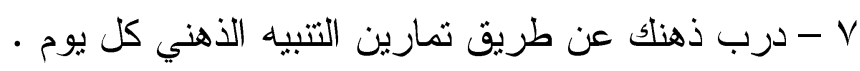

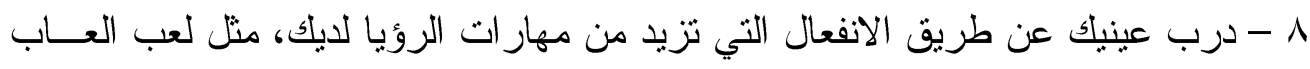

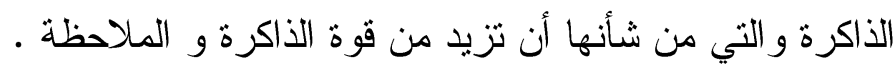

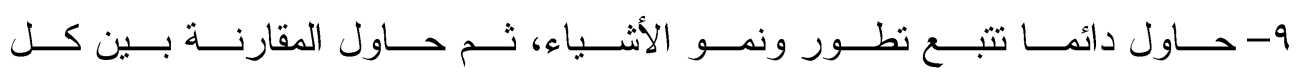

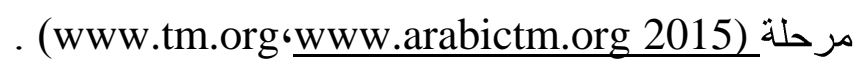

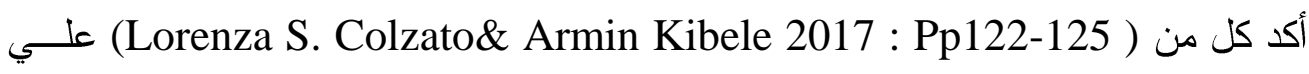

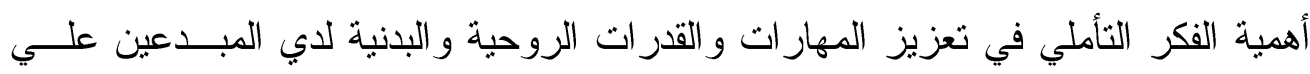

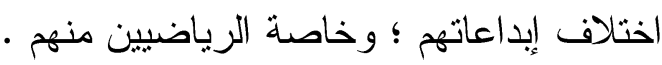


ويمكن تتمية القدرات التأملية عند المبدع (المصمم) بما بسمى بتقنية التأمـل التجـاوزي،

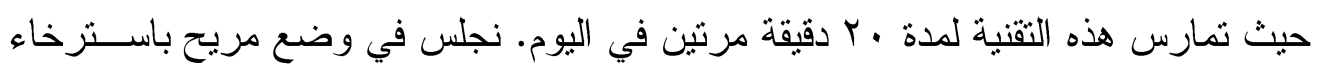

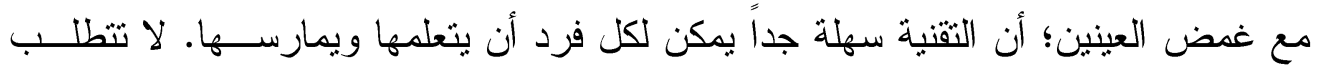

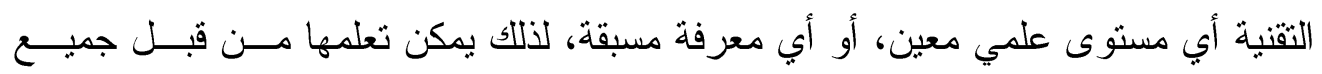

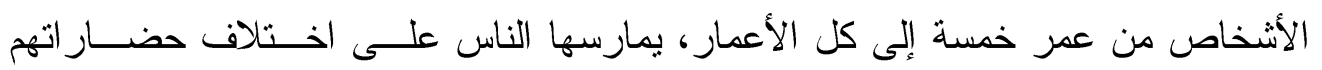

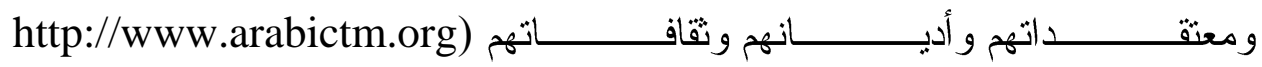

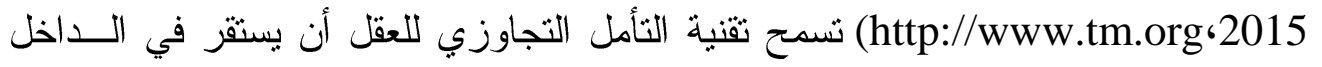

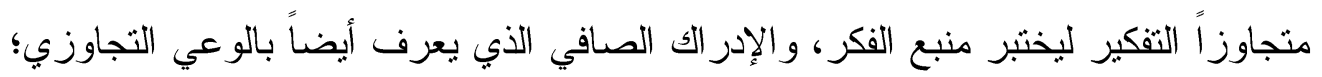

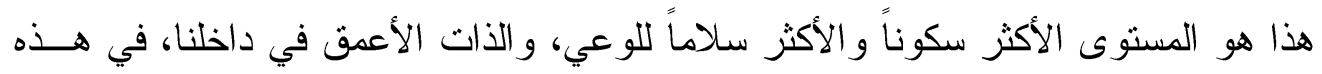

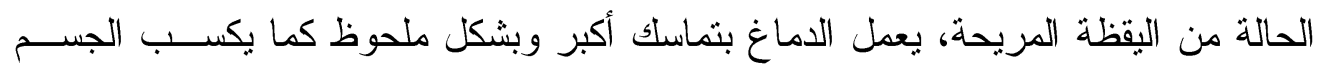

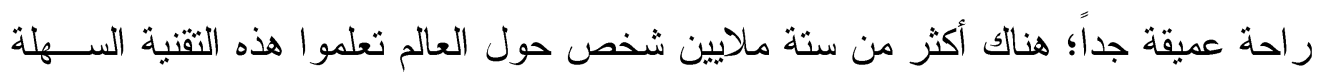

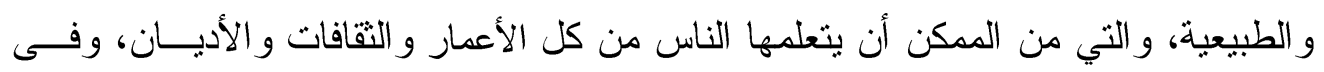
مختلف الأوطان و التي تساعد على تتمية الفكر التأملي

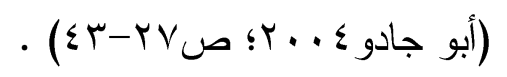

*- أما إجابة السؤال الثاني ما هي المنافع التي تعود على الإنسان و المبدع شديد الملاحظة

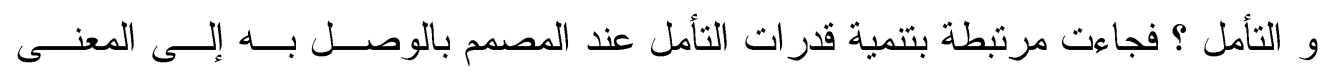

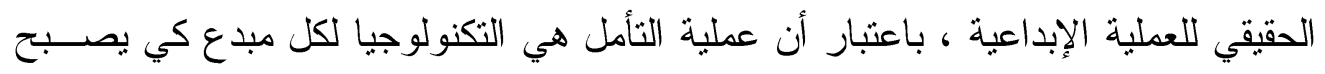

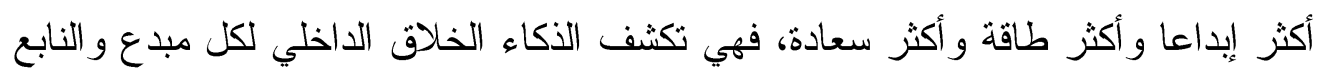

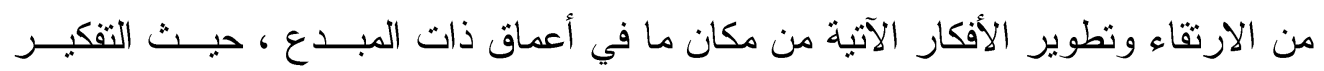

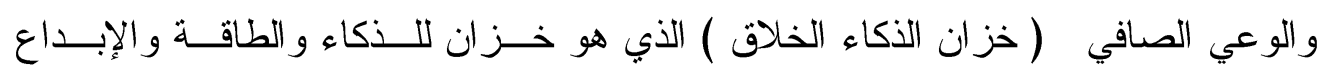
اللامحدود (http://www.tm.org2015،http://www.arabictm.org2015). تتمي تقنية التأمل التجاوزي الطاقة الفكرية بالكامل، وكذا وضوح الإدراك بطريقة طبيعية؛

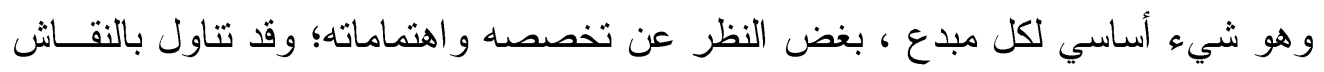

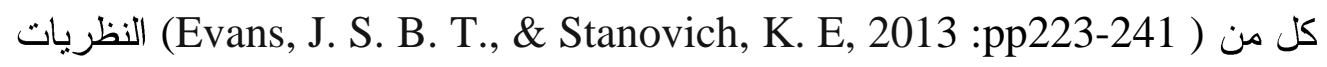
العملية المزدوجة في عمليات التذوق و الإدر الك، و أهمية ذلك بتتمية الوعي وتتمية الأدر الك.

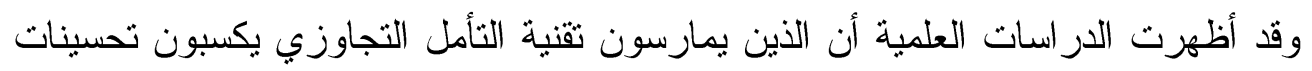
كثيرة في طاقتهم العقلية منها على سبيل المثال ازدياد الذكاء 
(http://www.tm.org 2015 ، http://www.arabictm.org2015) و الإبداع، وتحسّن الذاكرة ويتجلى ذلك فيما يلي: 1- توسع وتحسين قدرة الفهم و التركيز . r- تحسن الأداء الأكاديمي فعالية أكبر و أكثر إنجاز اً في الحياة المهنية. ب- مستويات أعلى من الخلق و الابتكار .

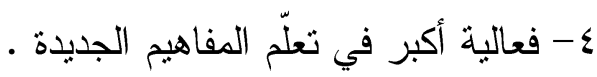

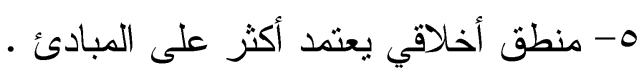

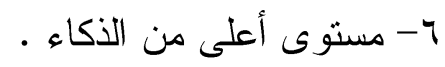

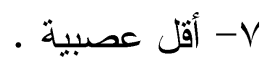
人- زيادة الكفاءة في الجهاز العصبي • •

العلاقة بين المبدع(المصمم) والانفعال التأملي:

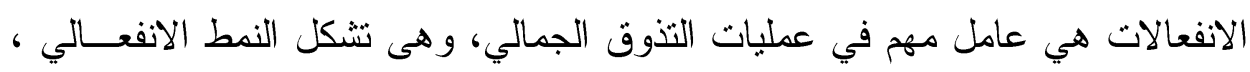

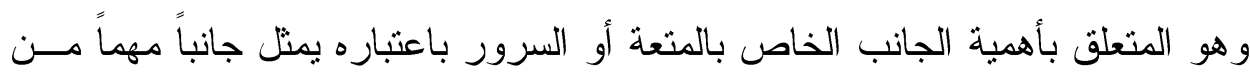

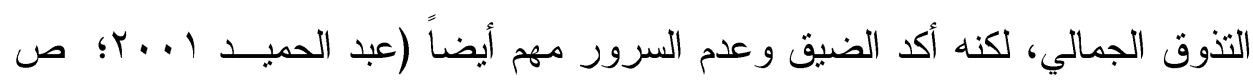
. $(0 \leq \varepsilon$ وقال فر اينفلس"أن اللوحة التي تستثير المتعة أو السرور فقط؛ هي غالباً لوحات تفتقـر

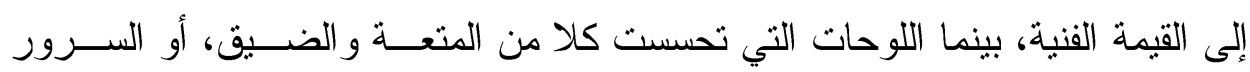

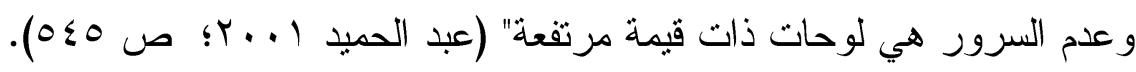

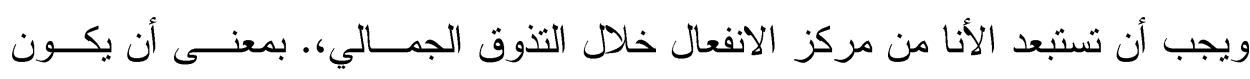

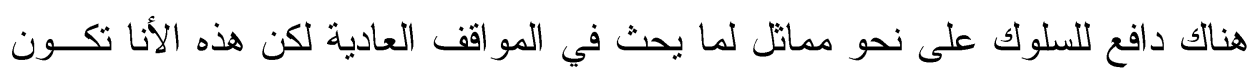

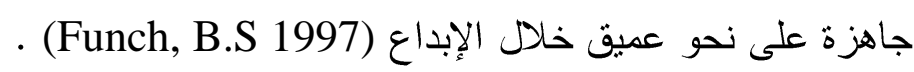
و أكـد (Dilwar Hussain \& nd Braj Bhushan 2010, 10, 3, pp. 439-451)

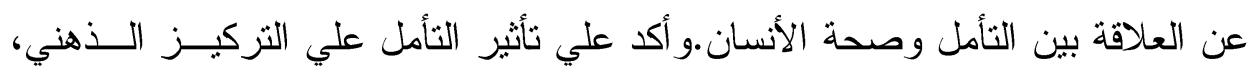

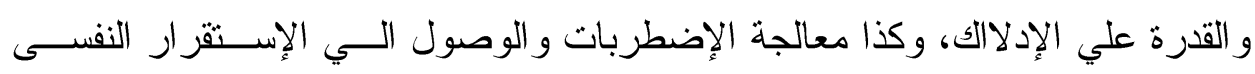
و العقلي. و الذي له تأثير مباشر علي الصجة الجسدية و النفسية للإنسان. 


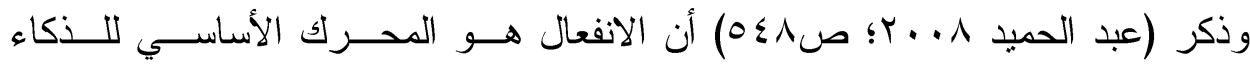

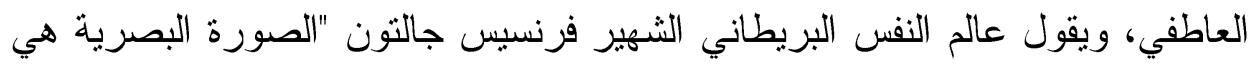

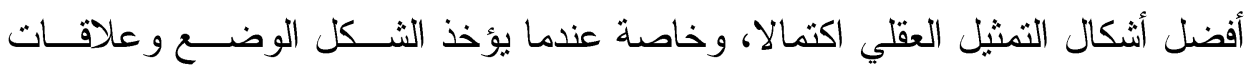

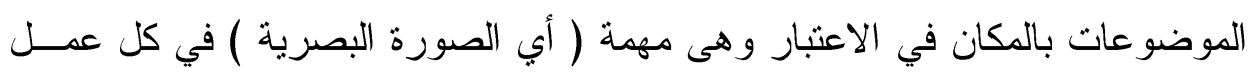
يدوي، وفي كل مهنه حين يكون التصميم مطلوباً."

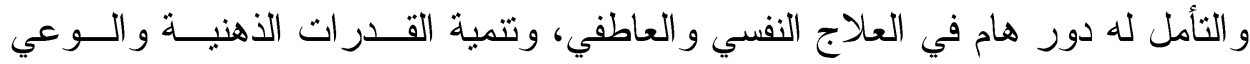
الإدر اكي للمبدع(الفنان امصمم) في جميع المجالات ومنها بطبيعة الحال فــي مجــــال الفنون و التصميم علي لإختلاف أنو اعة ؛ وتثقوم الفنون بتركيز الانتباه و الطاقة، وتساعد

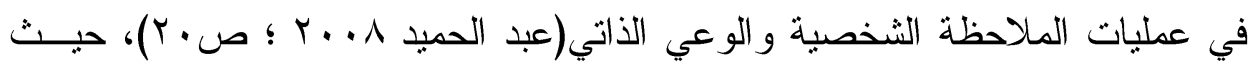
تمثل الفنون ظاهرة إنسانية عامة وسائل للتخاطب الإنساني.

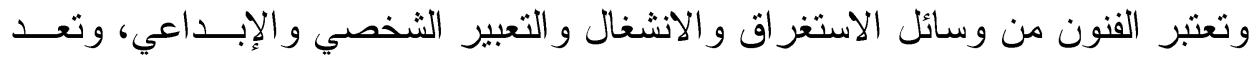

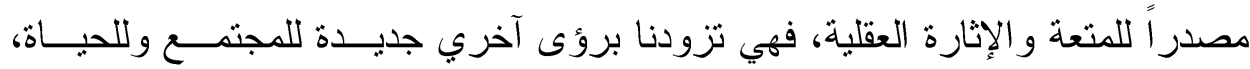

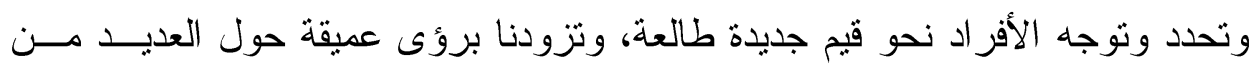

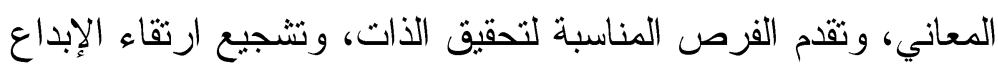

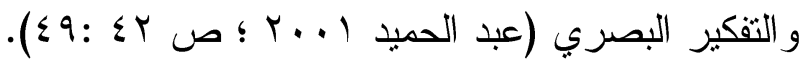

\section{التأمل و التفكر في القر عان الكريم والسنة التبوية الثريفة:}

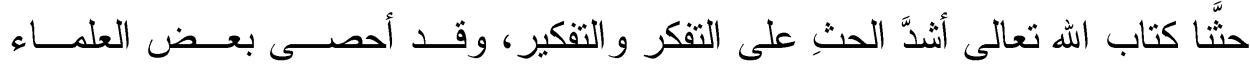

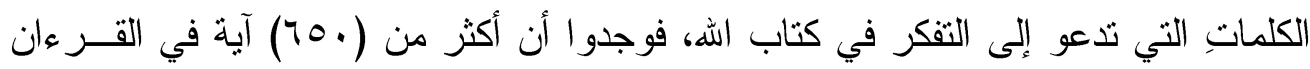
الكريم تحث على التقكر و التدبر و التعقل و النظر و التأمل، فكتاب الله تعالى هو أكبر هادٍ لنا لنا

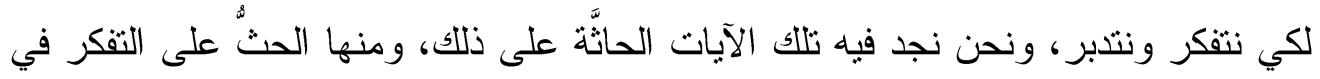

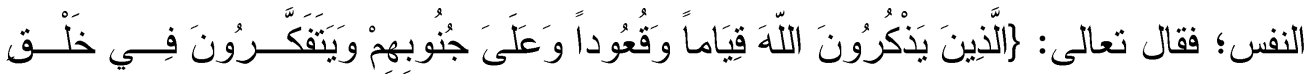

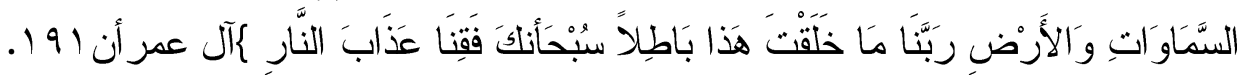

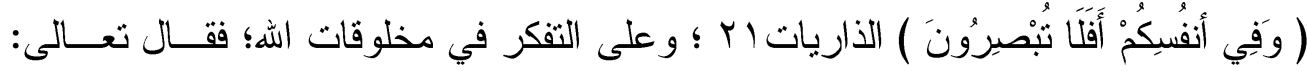

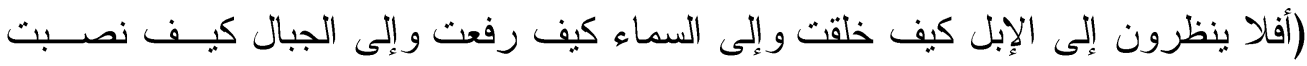

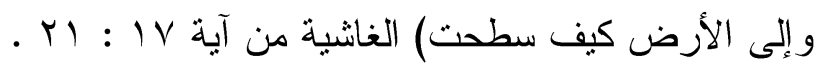




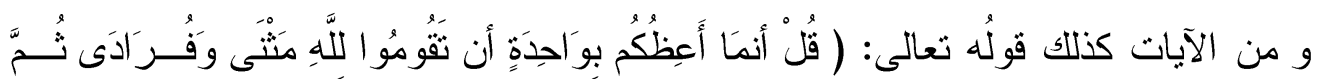

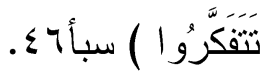

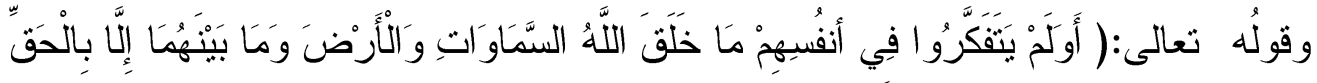

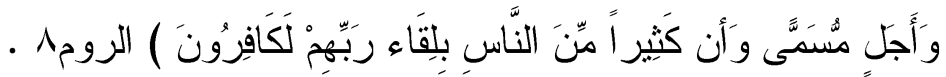

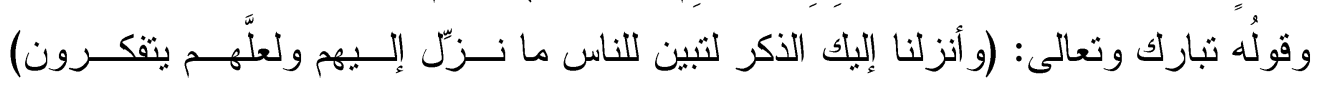

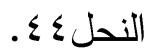

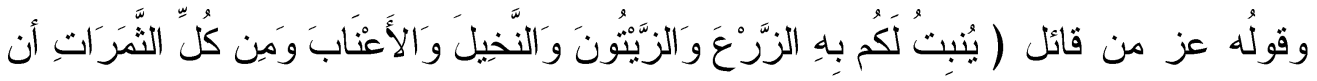

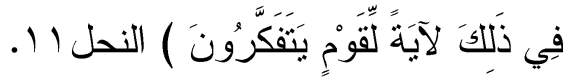

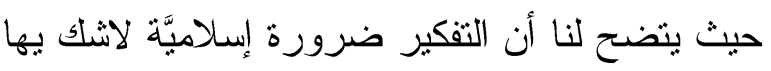
(http://www.saaid.net/Doat/khabab/62.htm 2016)؛ ومن نماذج تطبيق التفكير

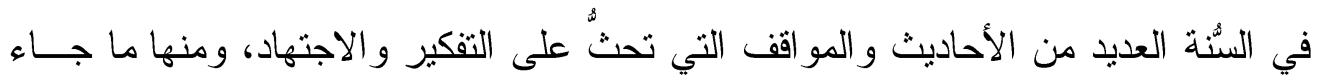

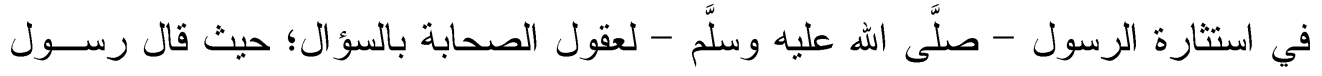

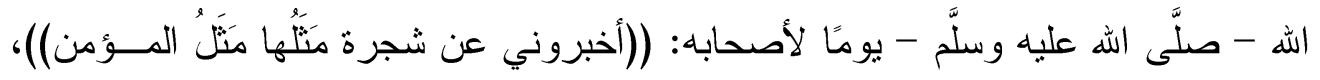

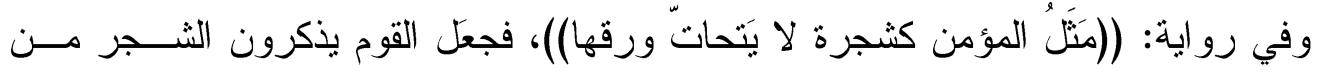

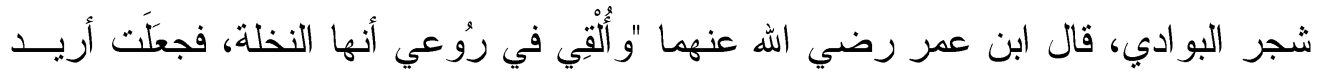

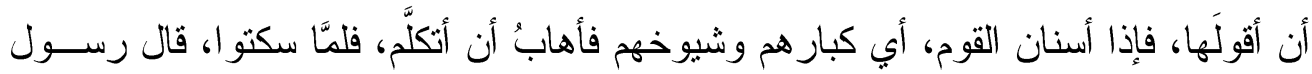

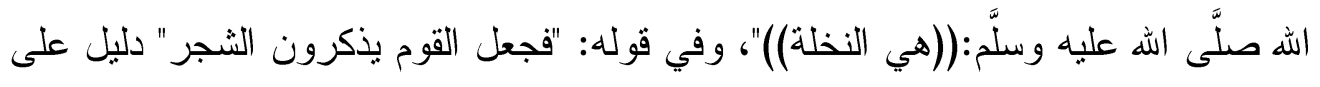
إعمال العقل، و إطلاق التفكير . (http://muntada.islamtoday.net، http://www.islam-qa.com 2016 ) ويُميّز التفكير في الإسلام انضباطه بضو ابط العقيدة و الفطرة السليمة، و التفكير فيما يجـوز

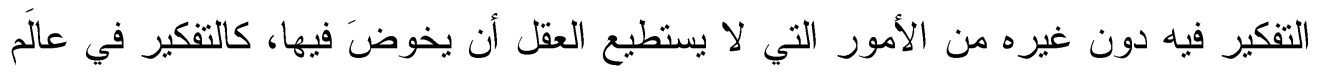

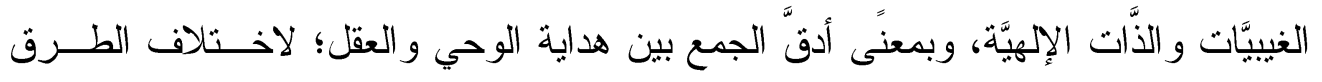
التي يعتمد عليها التفكير للوصول إلى حقائقها.

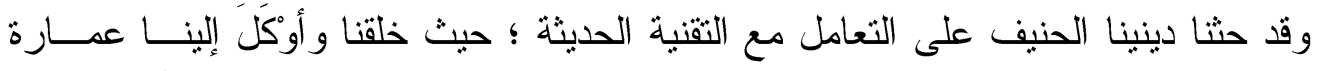

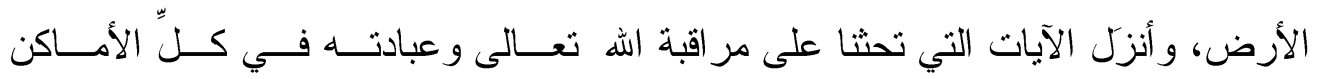

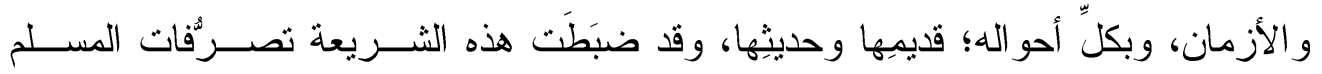

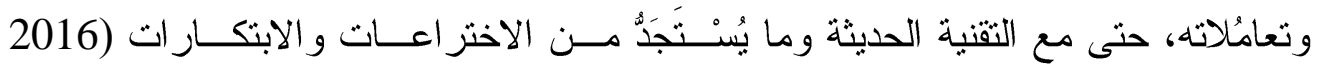




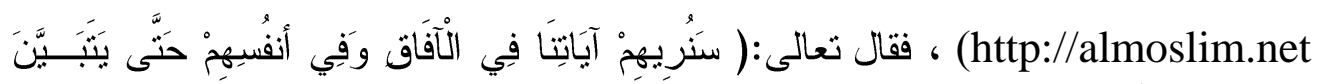

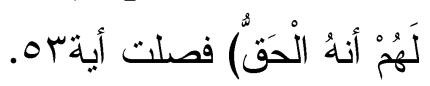

\section{العلاقة بين المصم المتأمل والعملية الإبداعية:}

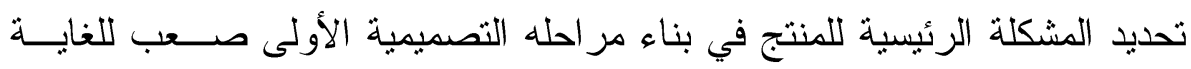

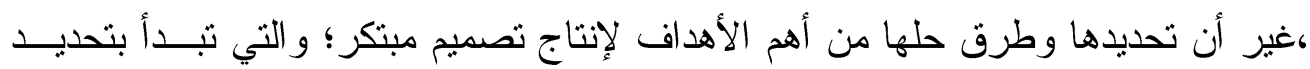

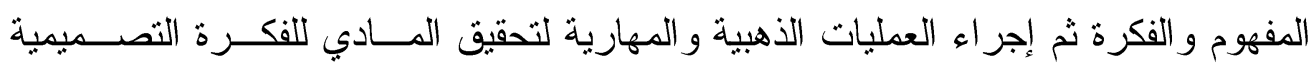

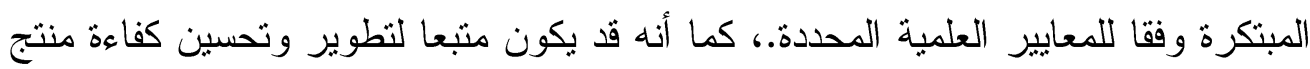

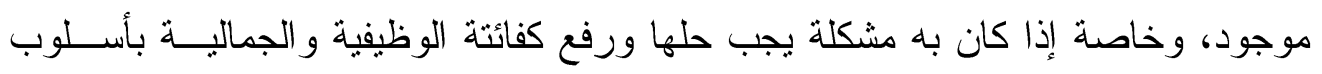

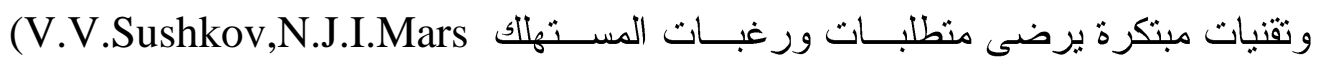

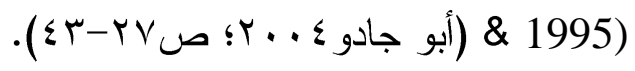

مفهوم الحل الإبداعي للمشكلات التصميمية: يقوم الحل الإبداعي للمشكلات التي تو اجه المصمم على ركائز يكون فيها التأمسل التهل

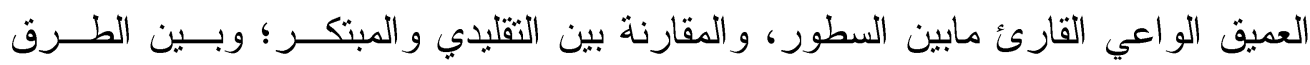

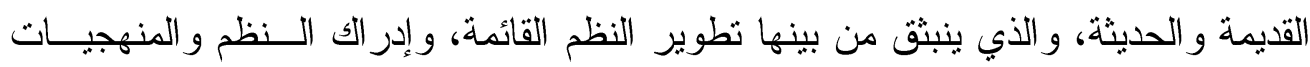

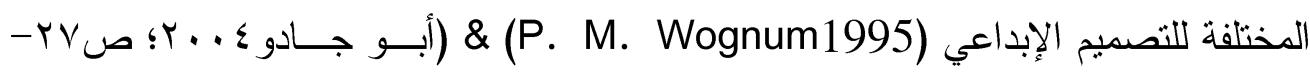
. ( $\leqslant r$

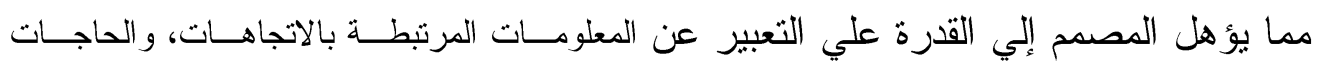

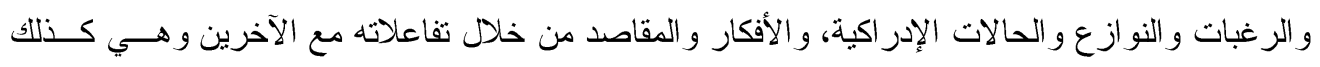

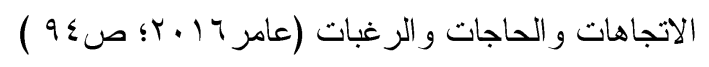

\section{الأساليب المنهجية للتصميم الإبداعي:}

تبدأ منهجية الإبداع لدى المصمم المنأمل شديد الملاحظة من إدر اكه الو اعي بالنظم

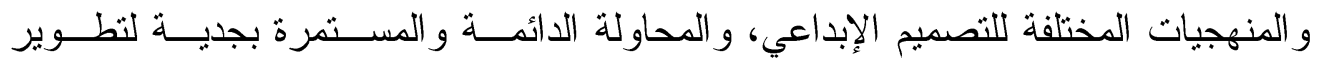
وتحسـين (أبــ (V. V. Sushkov, N. J. I. Mars \& P. M.Wognum1995)

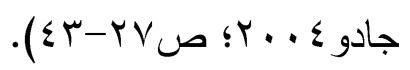




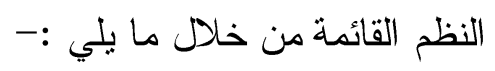
1- العصف الذهني للمصمم و المبدع من خلال التأمل لما يحيط بـه من متغير ات، ومتطلبات المنتلقي. r- اقتر اح طرق نفسية وتقنية لتعزيز القدر ات البشرية في البحث عن حلول خلاقة.

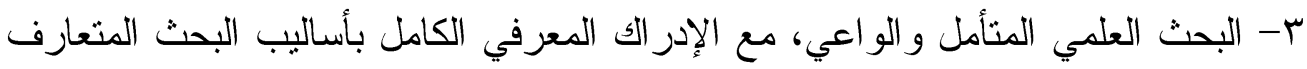

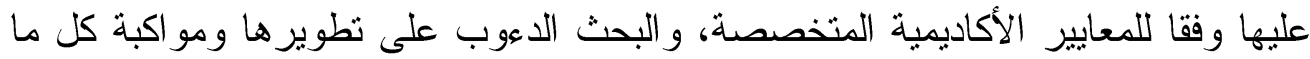
هو حديث في مجال التخصص. ع- ضرورة معرفة الإستر اتيجية المعرفية، وكيفية التعامل مع المعلومات المادية و التصميم للحصول على أفضل حل. 0- الاستتاد إلى المنهج العلمي الحديث في استخدام رسومات توضيحية و نمذجة التصــميم قبل البدء في عمليات التنفيذ النهائي . צ- انتهاج مختلف تقنيات حل المشكلات على أساس الاطر اد الذي يحتوي علــى تقنيـات تحليل الحالات الأولية ، و استخر اج المشكلة الرئيسية التي يتعين حلها.

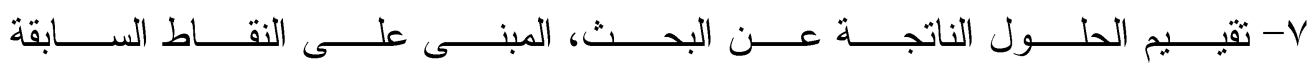
.(Una Halligan Chairperson 2009)

\section{مهارات في التأمل والإبداع:}

يمكن أن يكون من الصعب التقكير في الإبداع، أو مهارة تطبيق الخيال في الو اقع، و القدرة على التتبؤ من خلال تعريف واحد ؛ حيث التصميم و العمل الفني المبتكر هي القدرة على تتفيذ نتائج محددة مسبقا في كثير من الأحبان، لذا من الصــعوبة بمكــان أن يــدرس

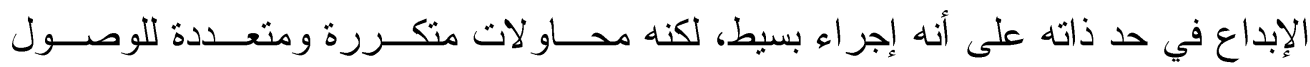
للأفضل (Una Halligan Chairperson2009). تأتي الغالبية العظمى من الأعمال الإبداع من إيجاد طرق جديدة للجمع بين الأفكار

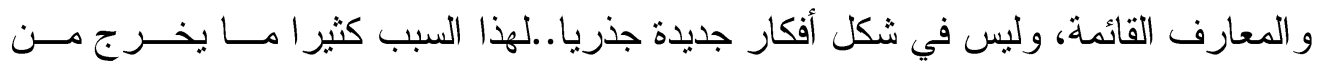

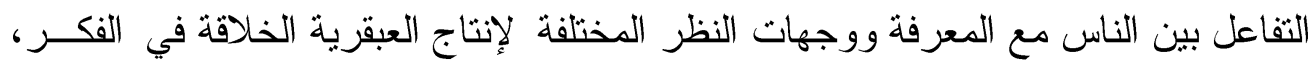


و المنتجات الجديدة المبنكرة ( ملتقى عـلم التفكيــــر و الإبداع لبر امج ومهــار ات التفكيـر

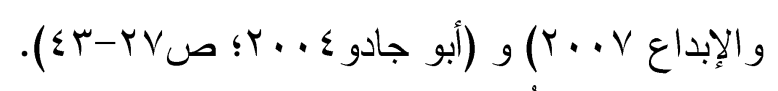

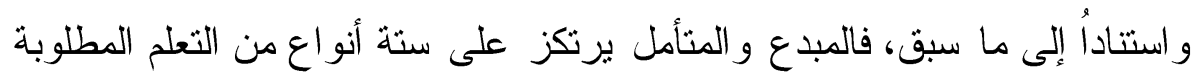

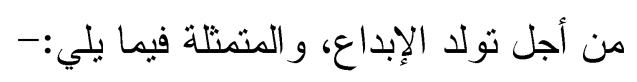

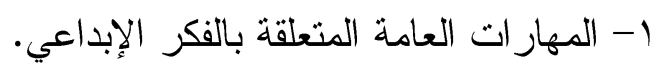

r- الخبرة القائمة على القو اعد و المعايير العلمية للعملية الإبداعية. ب- القدرة على العمل مع مناطق أخرى من الخبرة.

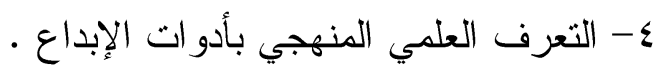
0- التذريب المتطور و المستمر على الإبداع. צ- إدارة الابتكار و الإبداع بأسلوب علمي وفقاً للمناهج ذات ذات الصلة......الخ.

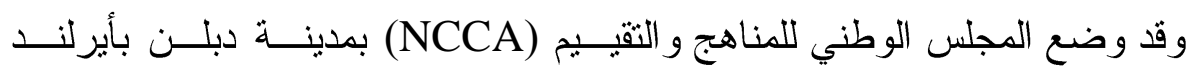
(National Council for Curriculum and Assessment 2017) الأساسية في دورة العليا، حيث حدد أن كل مهارة مرتبطة بعدد من العناصر ، كـلـل و احــدة

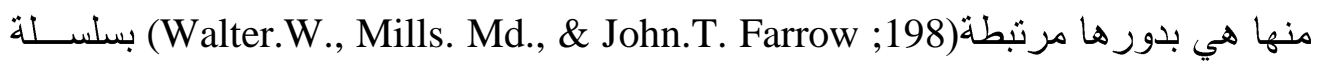
من نتائج التعلم، و المتبلورة في المهار ات الرئيسية التي حددها الإطار جاءت كالآتي: 1- 1 - مهارة معالجة المعلومات. r- مهارة التفكير الإبداعي و النقدي. r- مهارة التو اصل مع كل ذو صلة. ـ- مهارة العمل مع الآخرين في فريق عمل متجانس.

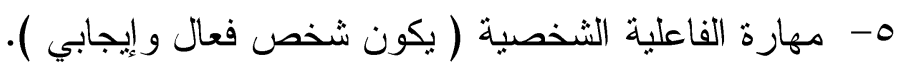

وقد أسهم التتوع الثقافي إيجابياً في تتوع وجهات النظر المطروحة لقضية ما، مما بيــاعد

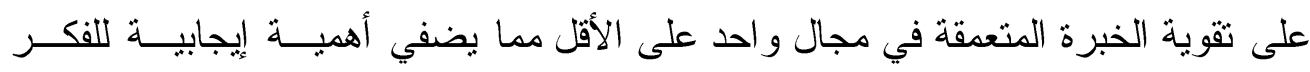

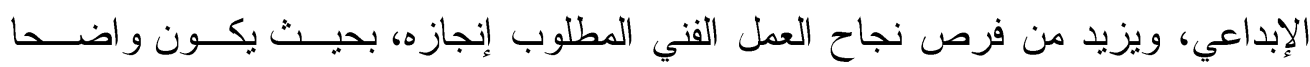

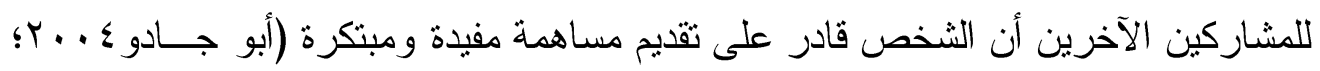

$$
\text { \&( } \& \text { ص }
$$

(National Council for Curriculum and Assessment 2017) 


\section{نماذج تصميمية نتاج مهارات التأمل و الإبداع :}

قامت الدر اسة بإجر اء مقارنة بين تصميمات بعض المنتجات الصـــناعية و الفنــــة

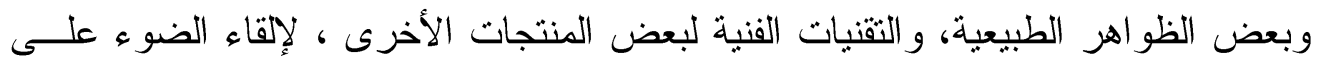

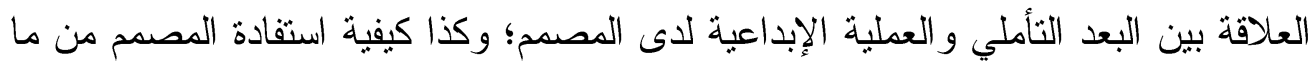
بحيط به من ظو اهر، ومنتجات، ومتطلبات المستهلك. لكن.

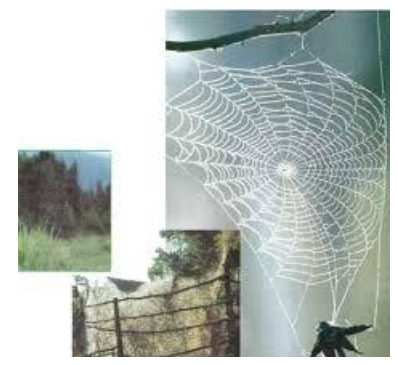

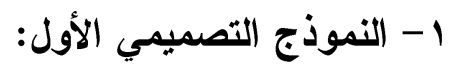

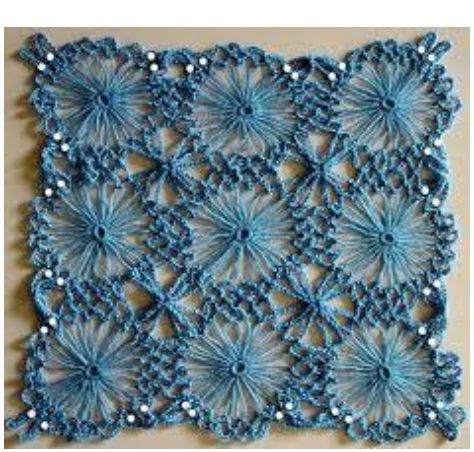

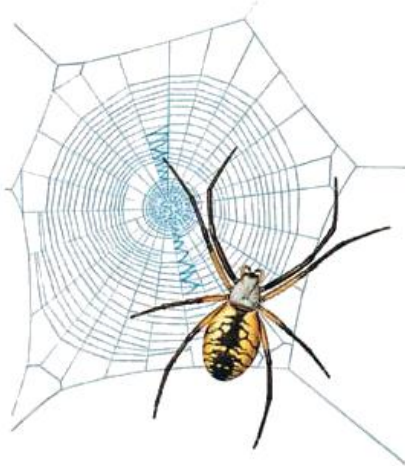

شكل (r)

يوضح نسج العنكبوت لبناء بيته

https://www.google.jo/search?q المصدر جنوبن

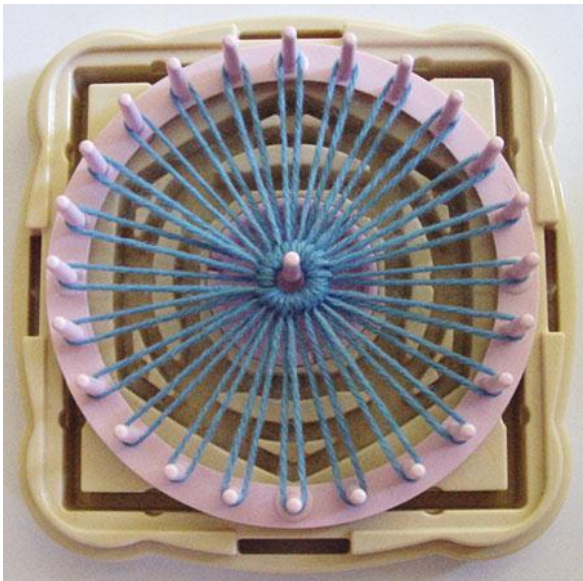

شكل (1)

تصميم لأحد المنتجات النسجية بتأمله يتضح وجه الثنبه

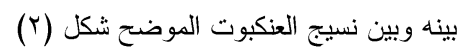
المصدر

http://goldenhandmade.forumarabia.com 


\section{ا - 1 دراسة تحليلية للنموذج التصميمي الأول :}

يلاحظ من الدراسة التحليلية للأشكال، و الكائنات، و الظواهر اهر الطبيعية، والتـي اســتنبط منها المصمم منتجه الفني و الذي تتآلف خاماتة من خيوط نسجية صــناعية (عـامر 10 • ب:

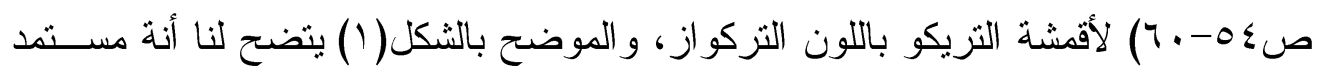

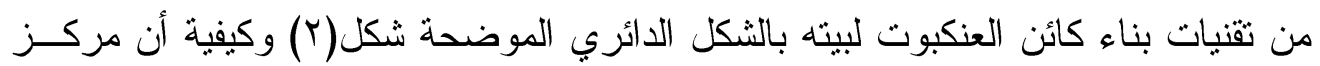

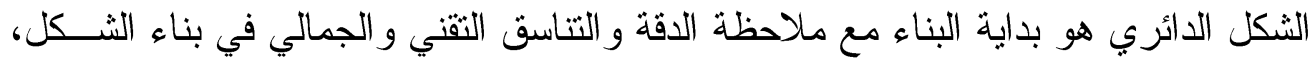
و هذا يبين لنا مدى أهمية تتمية مهار ات المصمم التأملية، و الاستفادة و الاستلهام بما يحيط به وله

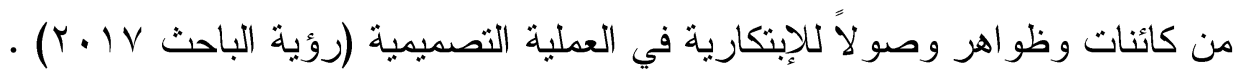
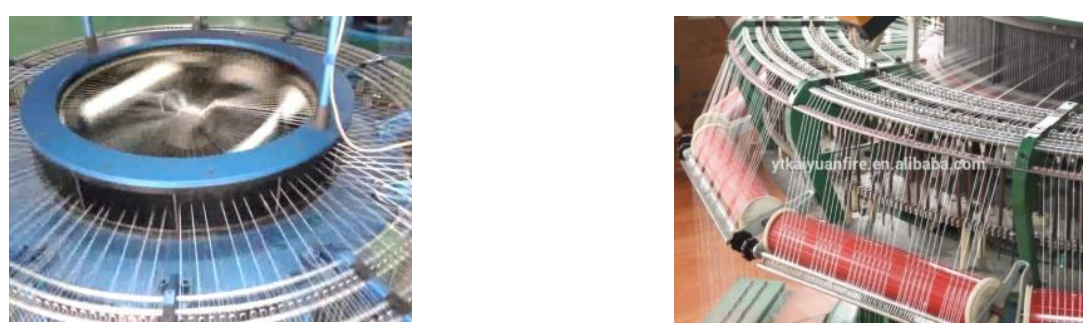

شكل (ץ)

يوضح تصميم ماكينات التريكو الدائري ويتضح مدى العلاقة بين ترتيب الخيوط على الأسطو انة الدائرية الرئيسية للماكينة

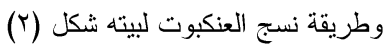

https://indonesian.alibaba.com/product : المصدر

(Akaydin M.,2009;34:26-30)

r - إسة تحليلية للنموذج التصميمي الثاني:

يلاحظ بتحليل النموذج التصميمي الثاني و الموضح بالثكل (ب) مدى العلاقة بين تصميم ماكينات إنتاج أقمشة التزيكو الدائري، وخاصةً في ترتيب الخيوط على الأسطو انة الدائريــة

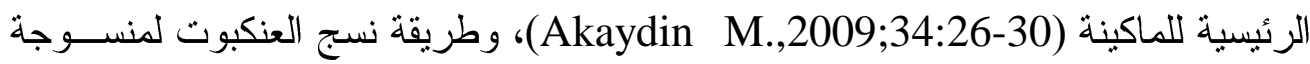

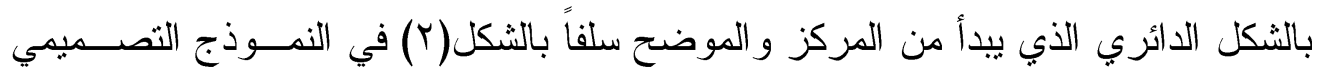

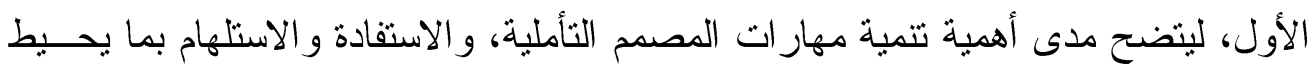

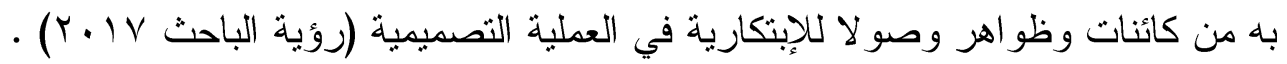


r- النموذج التصميمي الثالث:
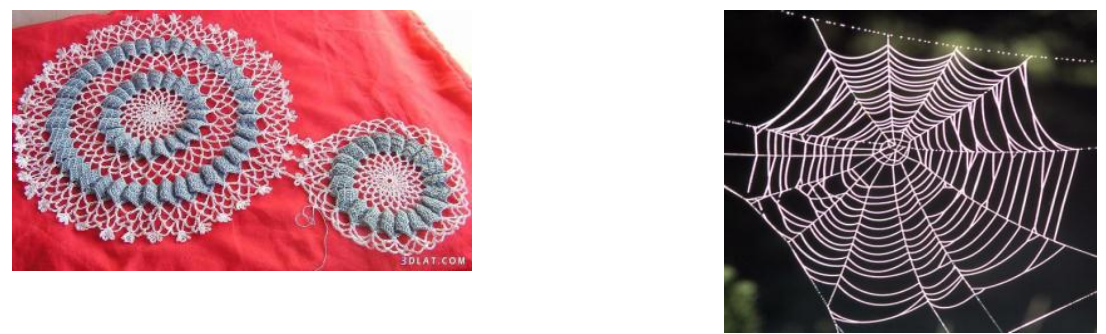

شكل (๕)

يوضح مدى العلاقة بين تصميم أحد منتجات الدانتيلا، ومنسوج العنكبوت

المصدر: Spider webs found to attract insects Online http://www.hayah.cc/forum/t38408.html
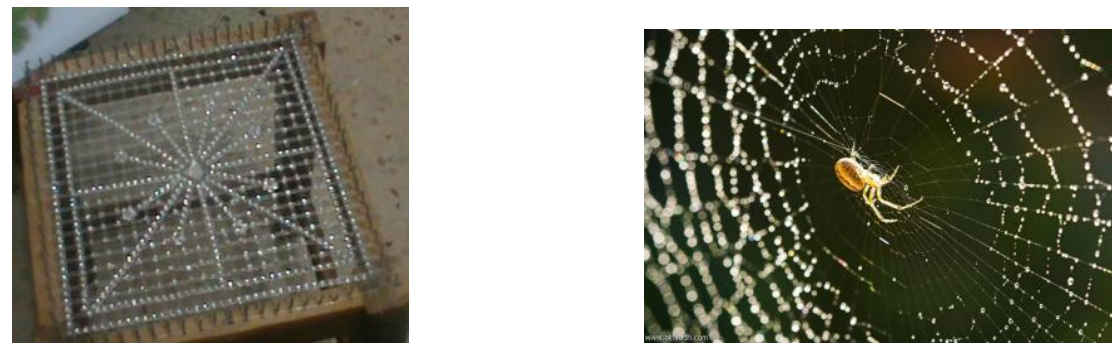

\section{شكل (0)}

يوضح مدى العلاقة بين ثقنيات تصميم أحد منتجات الدانتيلا، وتقنيات نسيج العنكبوت

https://homestylene.com : المصدر

http://merahassi.wix.com/deco/apps/blog/nouveau-napperon

\section{r- 1 دراسة تحليلية للنموذج التصميمي الثالث :}

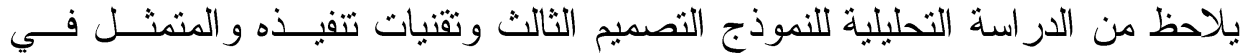

بعض نماذج للمنتجات النسجية الفنية كيف استتبط المصمح فكرتــه وتقتتيانــهـ مــن بنـــاء

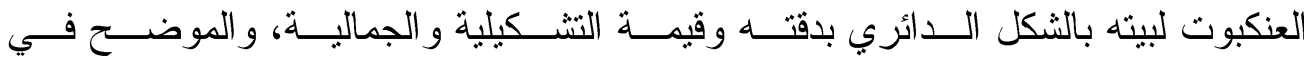
الأشكال(0، ع) ليتضح لنا جلياً مدى أهمبة تتمبة مهار ات المصــمم التأمليــة، و الاســتفادة و الاستلهام بما يحيط به من كائنات وظو اهر وصو لا للإبتكارية في العملية التصميمية (رؤية

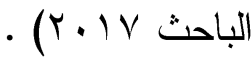


ع - النموذج التصميمي الرابع:
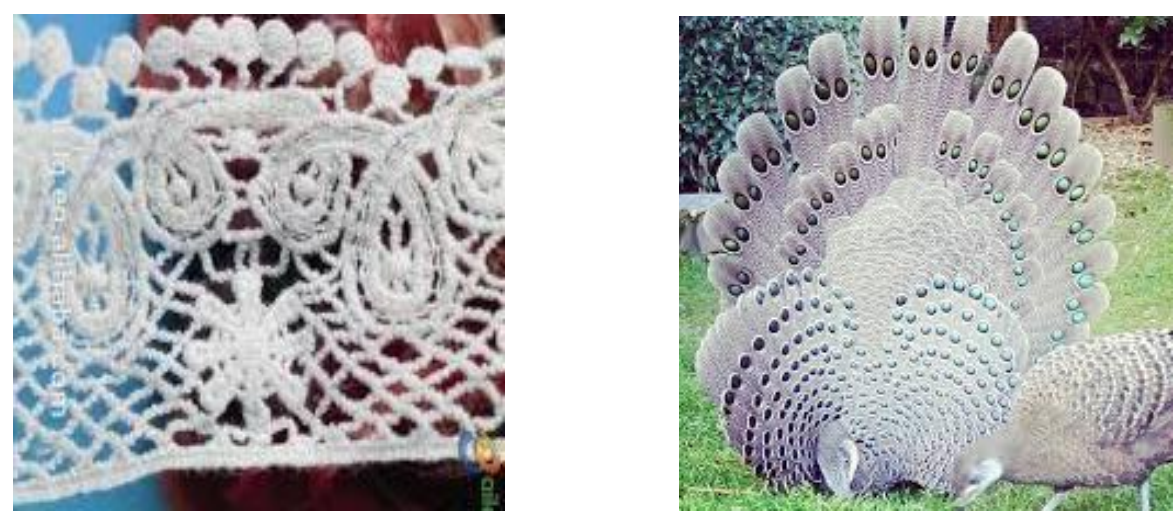

\section{شكل (1)}

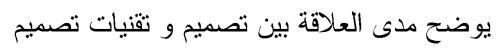

$$
\begin{aligned}
& \text { أحد منتجات الانتيلا ، المستلهمة من التثكيل الجمالي و اللوني لأحد الطيور }
\end{aligned}
$$

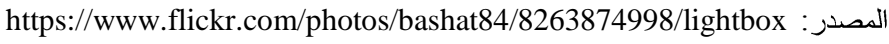

\section{ع - ادراسة تحليلية للنموذج التصميمي الرابع:}

يمثل النموذج التصميمي الر ابع الموضح بالثكل(آ) تصميم لأحد منتجات أقمشــة الـــانتيلا

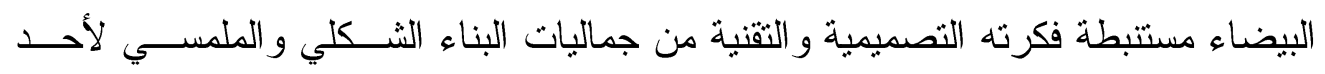

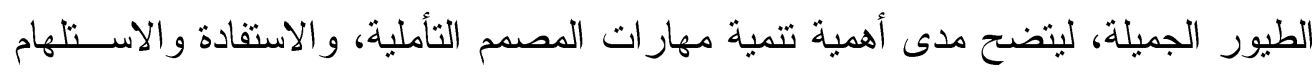

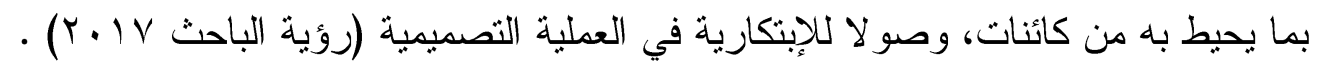




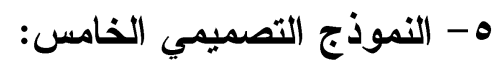
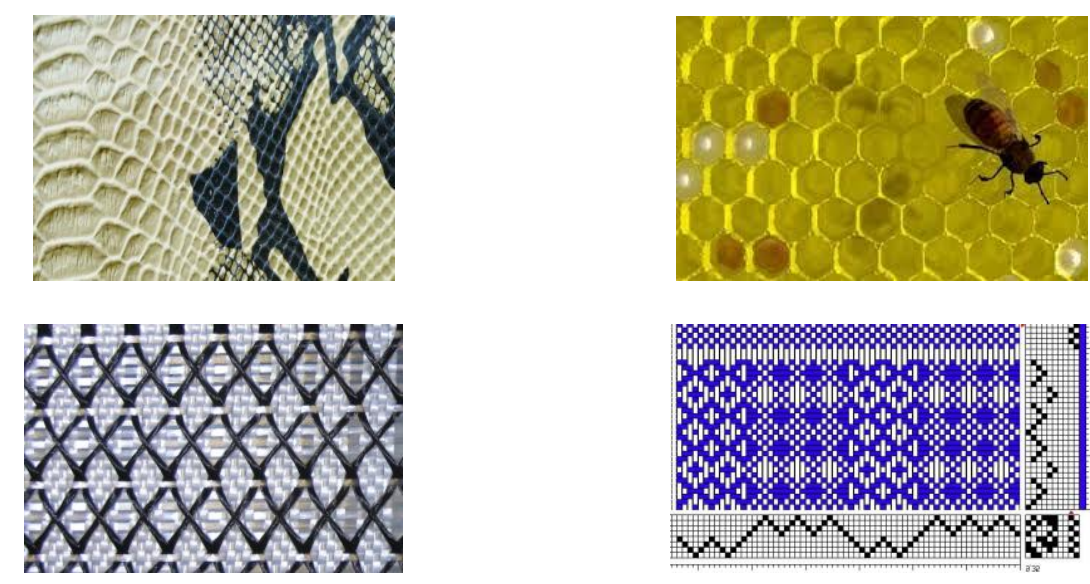

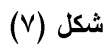

يوضح مدى العلاقة بين بناء نحل العسل لييته بما يسمى خلايا عسل النحل (Honeycomb)

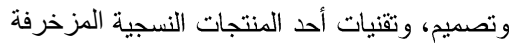

( Mostafa El Gamal, Mohamed. M .Amer; 2016 Pp 2-5): المصدر ونفيات وندئ

https://yurizone.wordpress.com/2009/12/13/kaajaiban-dari-sarang-lebah https://arabic.alibaba.com/product-detail/snake-texture-pig-skin-alligator-textur /http://laurasloom.blogspot.com/2011/03

http://thenewalphabet.com/radio/details7081.html

ه- 1 - دراسة تحليلية للنموذج التصميمي الخامس :

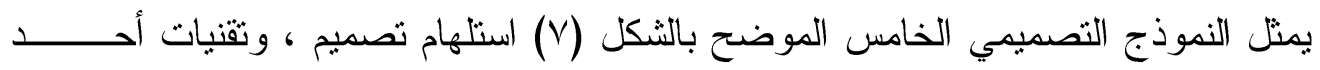

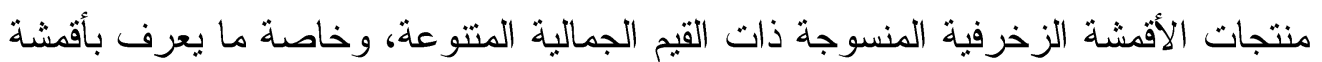
الدوبى المزخرفة بنقوش متعددة ومتتوعة نتيجة التتوع في تعاشق كل من خيـوط الســـــاء

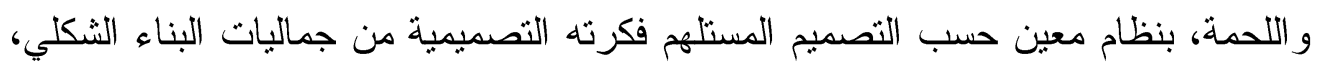

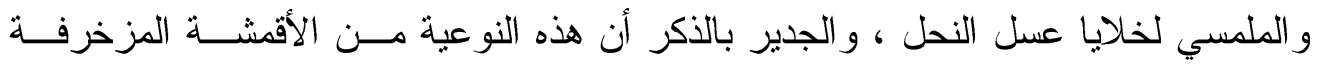
عرفت بما يسمى بالأسلوب النطبيقي النسجي خلايا النحل أو الهانيكوم (Honeycomb). (Mostafa El Gamal, Mohamed. M .Amer; 2016 Pp 2-5) أهمية تنمية مهار ات المصمم التأملية، و الاستفادة و الاستلهام بما يحـيط بــهـ مــن كائنـات

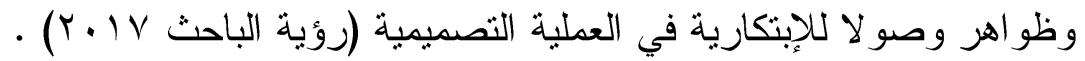




\section{צ- النموذج التصميمي السادس:}
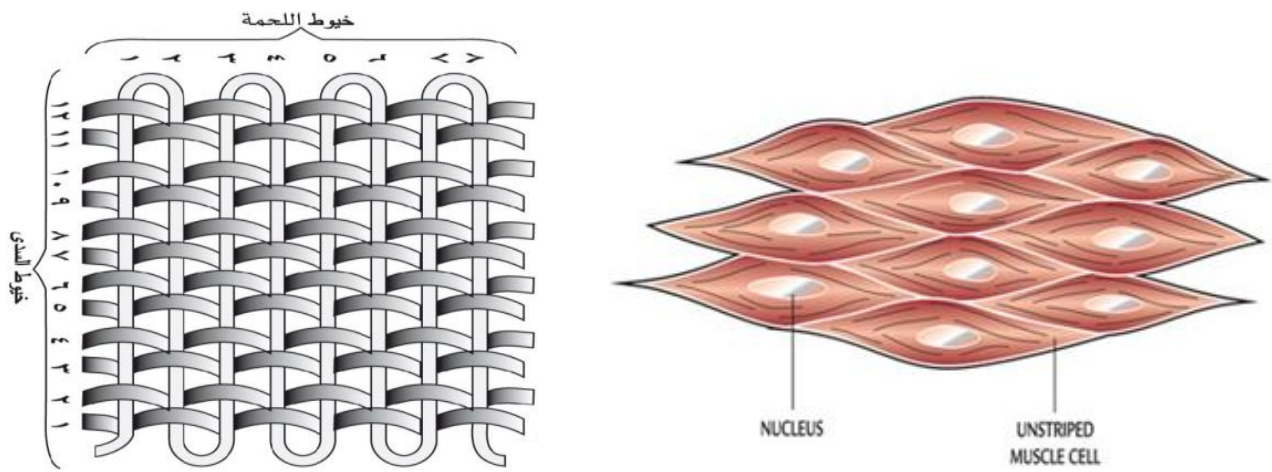

(^) شكل

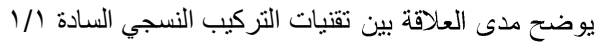

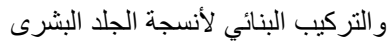

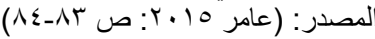

http://defenderauto.info/diagram-of-smooth-muscle

https://ar.wikipedia.org/wiki

צ- 1 دراسة تحليلية للنموذج التصميمي السادس :

يمــــــل النموذج التصميمي السادس و الموضـح بالثكل (^) العلاقة بين الثركيب البنـائي

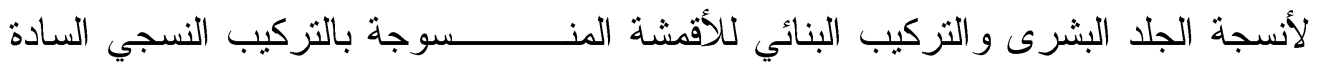

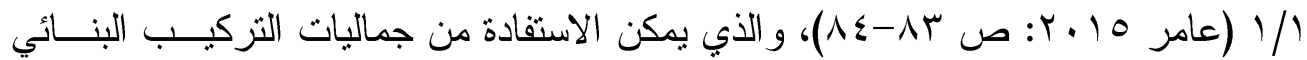
و الملمسي لأنسجة الجلد البشرى في تصميم الأقمشة المنسوجة ذات قيم جمالية واســتخداميه

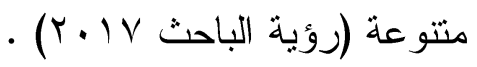




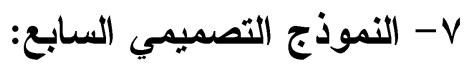
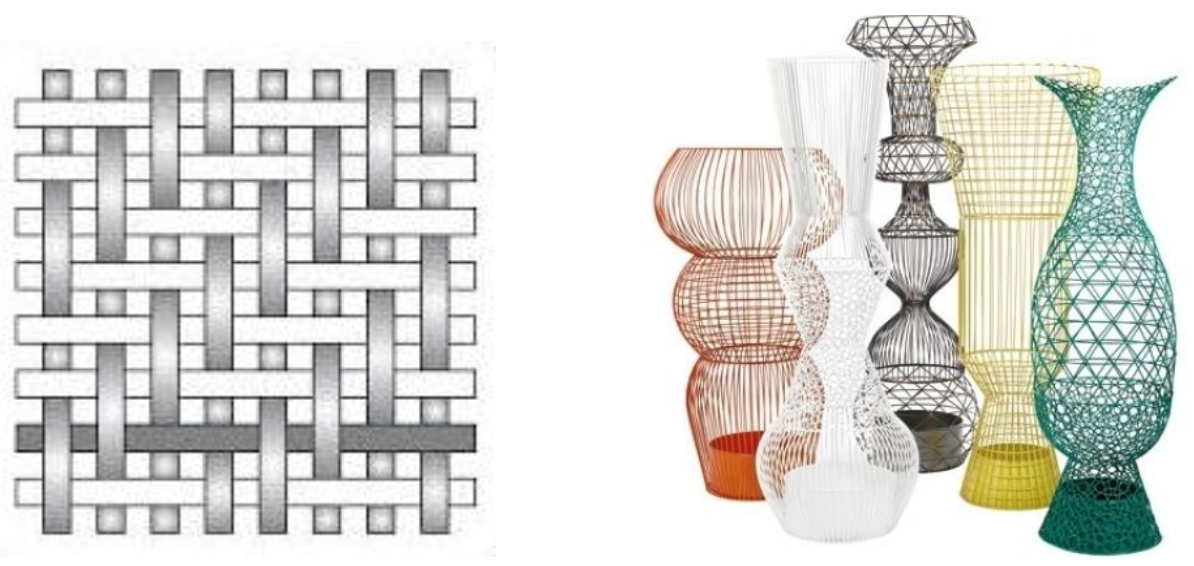

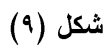

$$
\begin{aligned}
& \text { يوضح مدى العلاقة بين تقنيات التركيب النسجي السادة //1، وتصميم بعض المنتجات الصناعية } \\
& \text { (وخاصة وحدات الإضاءة) }
\end{aligned}
$$

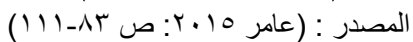

https://www.pinterest.com/pin/570901690243949557/?lp=true https://www.tes.com/lessons/tbwliJHgWmvnFQ/fashion-strategie

\section{1-V}

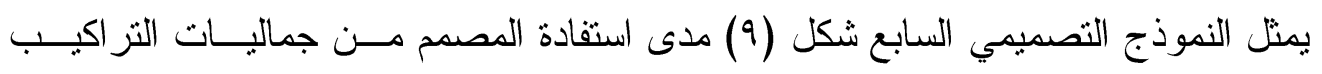

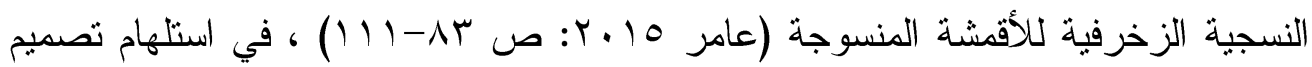
منتجات صناعية متتوعة القيم الجمالية وذات استخدامات متعددة وخاصة وحدات الإضاءة،

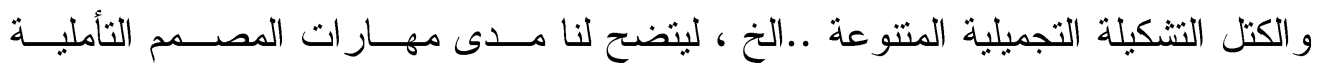

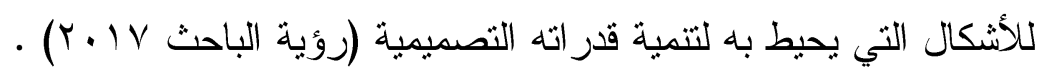




\section{^- النموذج التصميمي الثامن:}
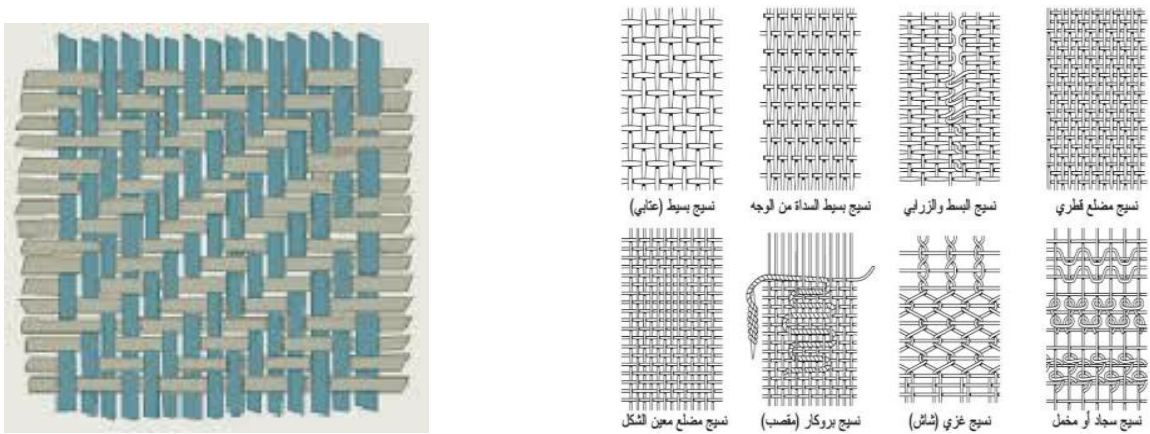

نسجع بيط لسداتة من لوجها

نبع البسط الزربي

تسيع مضلى نطري
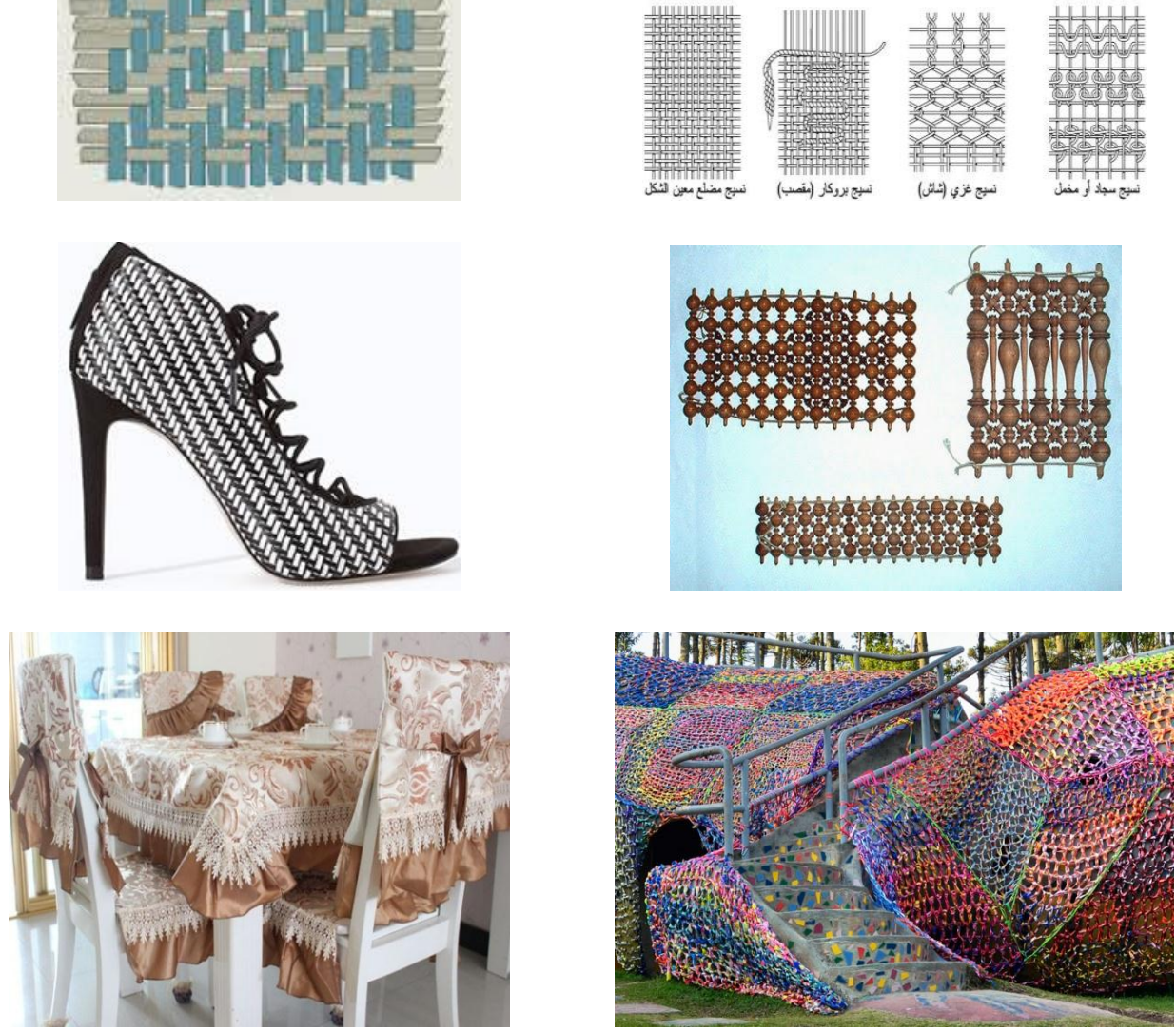

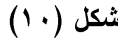

$$
\begin{aligned}
& \text { يوضح مدى الاستفادة من جماليات تصميم وتقنيات التر اكيب النسجية المتتو عة لبناء الأقمشة المتتوعة ، } \\
& \text { في تصميم بعض المنتجات الصناعية المختلفة }
\end{aligned}
$$

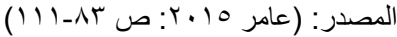

،(Mostafa El Gamal, Mohamed. M .Amer; 2016 Pp 2-20)

http://www.arab-ency.com///details.php?full=1\&nid=6215

$$
\text { http://yalalla.com }
$$

http://picshype.com/zara-shoes-summer-2014/effortless-chic.-zara-shoes/7259 https://forums.roro44.net/574275.html

/http://www.thisiscolossal.com/2012/07/crocheted-aligator-playground-in-sao-paulo-by-olek 


\section{1- ار داسة تحليلية للنموذج التصميمي الثامن :}

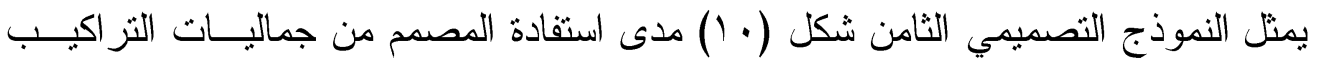

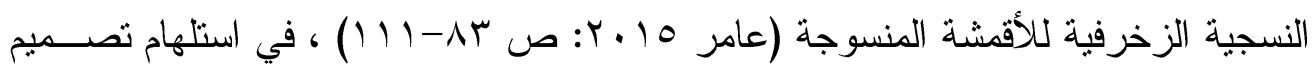

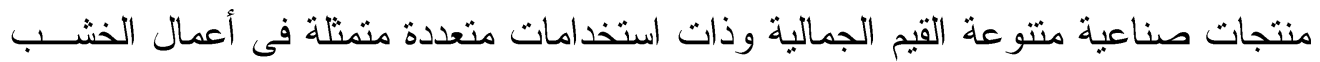

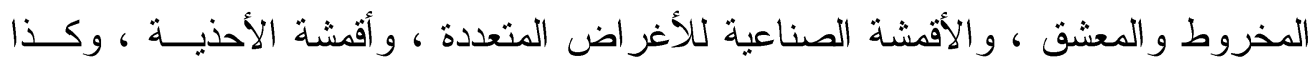

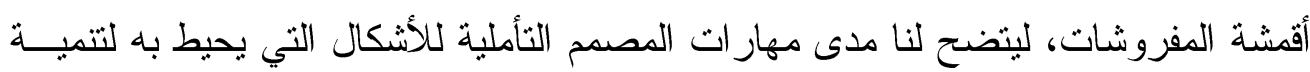

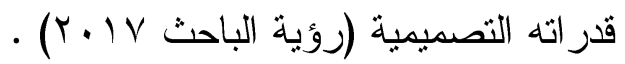

\section{9- النموذج التصميمي التاسع:}
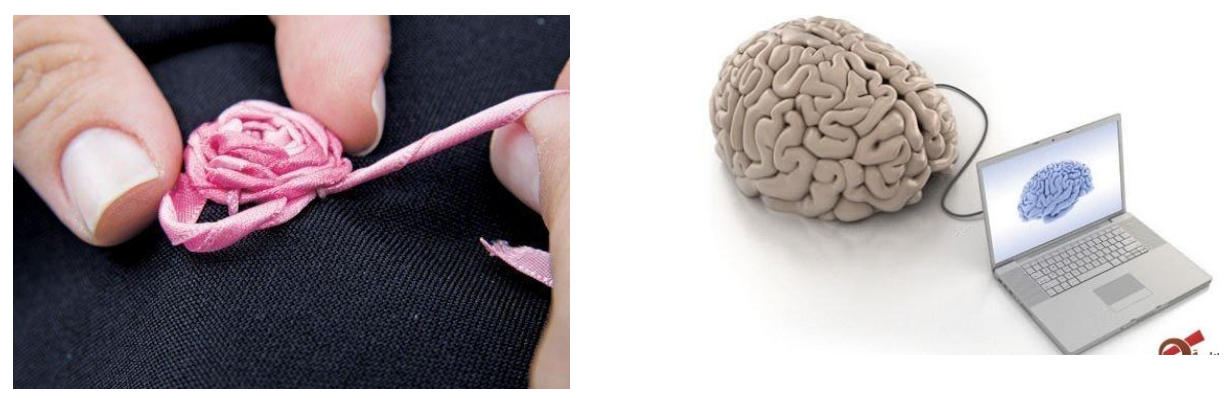

شكل (11)

تصميم مشغولة فنية مستوحاة من الثنكل البنائي لمتخ الإنسان

http://www.christian-guys.net/vb/showthread.php : المصن الردان

http://wonderfuldiy.com/wonderful-diy-embroidery-ribbon-rosette

9 - 1 در اسة تحليلية للنموذج التصميمي التاسع :

يمثل النموذج التصميمي التاسع الموضح شكل (11) مدى استفادة المصمم من الجماليات البنائية و الملمسية للثكل التشريحي لمخ الإنسان، في استلهام تصميم أثغال فنية متتوعة القـيم الجماليــة وذات استخدامات متعددة، ليتضح لنا مدى مهار ات المصمح التأملية للتركيب التشــريحى لأجــز اء

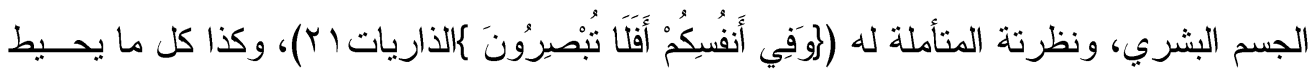
به لتتمية قدر اته التصميمية (رؤية الباحث 


\section{•}
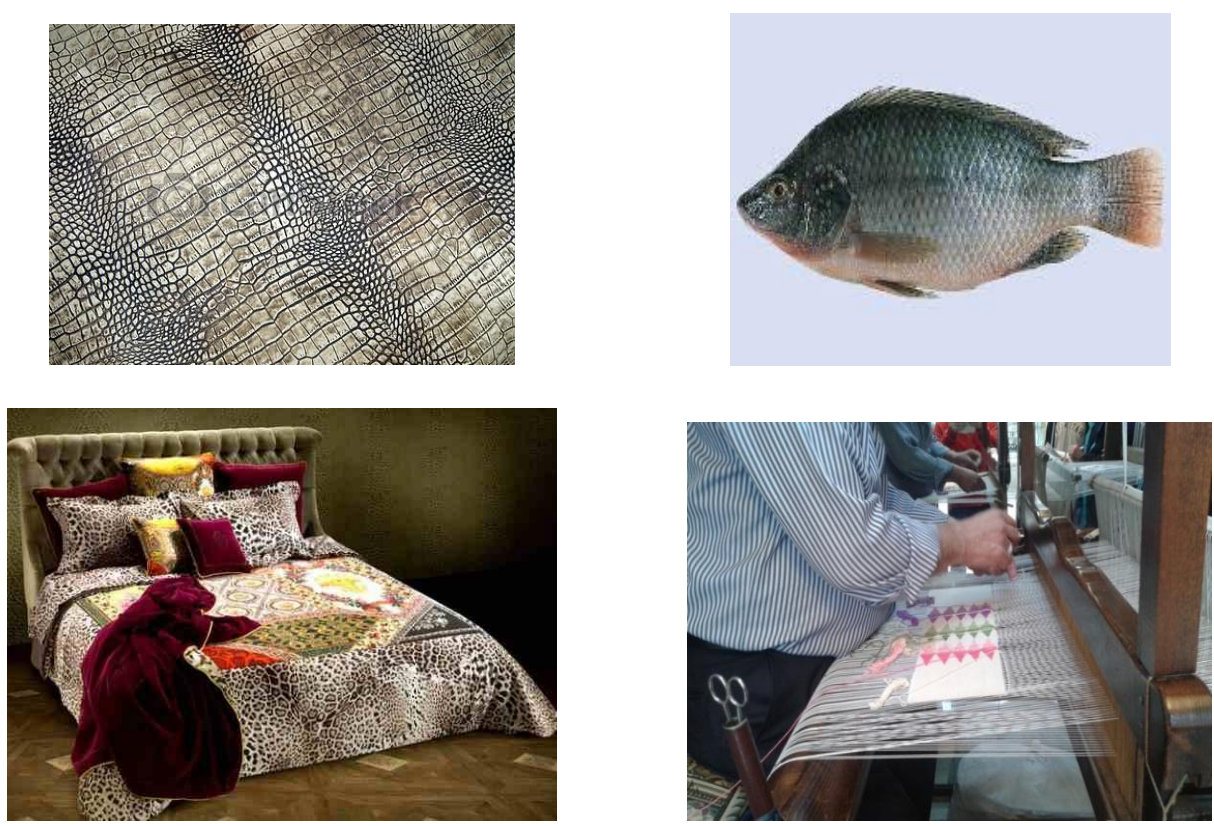

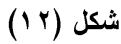

تصميمات منتجات نسجية مستوحاة من الثنكل النتّريحي، والملمسى لجلود الأسماك

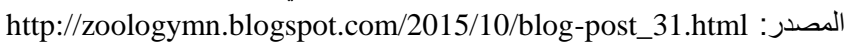
https://depositphotos.com

http://daahsha.blogspot.com/2015/11/2016_7.html

http://best-photo-egypt.xyz

\section{• 1 - 1 دراسة تحليلية للنموذج التصميمي العاشر:}

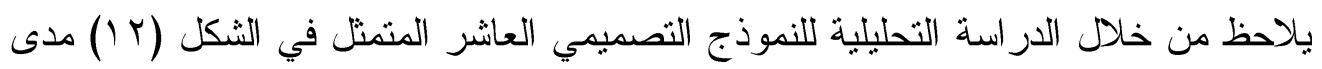

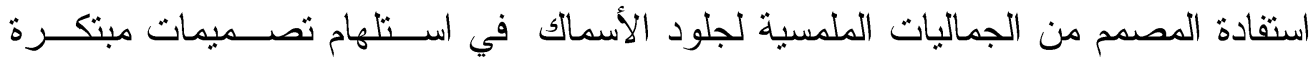

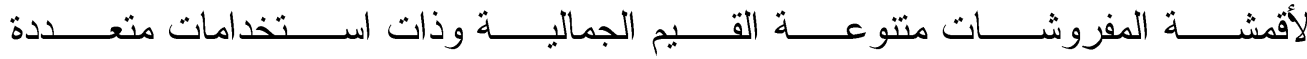
(Mostafa El Gamal, Mohamed. M .Amer; 2016 Pp 2-20) استفادة المصمم بما يحيط به من كائنات وظو اهر وصو لا للإبتكارية في العملية التصــميمية

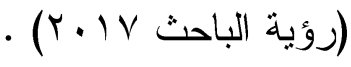




\section{1 - النموذج التصميمي الحادي عشر:}
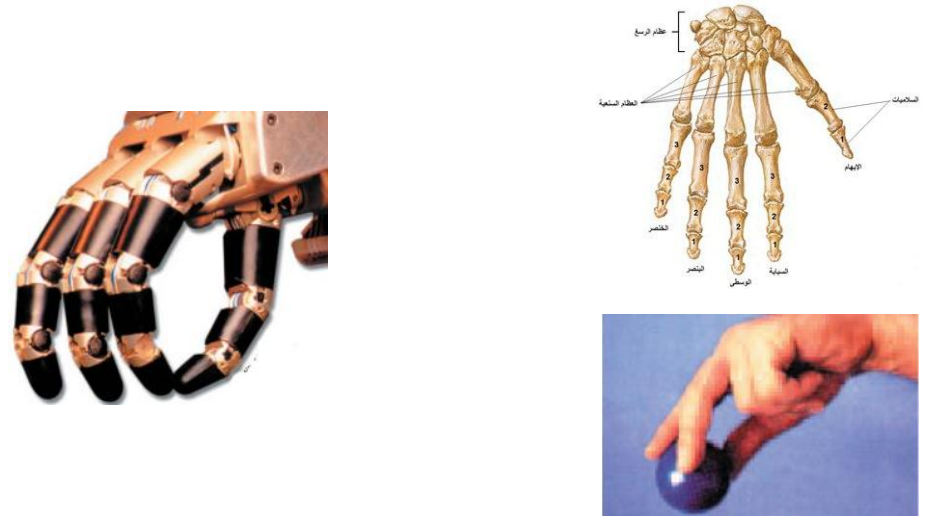

شكل (IT)

تصميم يد صناعية مستمدة من اليد الطبيعية

المصدر: www.rasulehasret.com/.../43997-bir-tasarimci-aklindaki http://www.nabulsi.com/blue/ar/art.php?art

$$
\text { هارون يحى التصميم والطبيعة }
$$
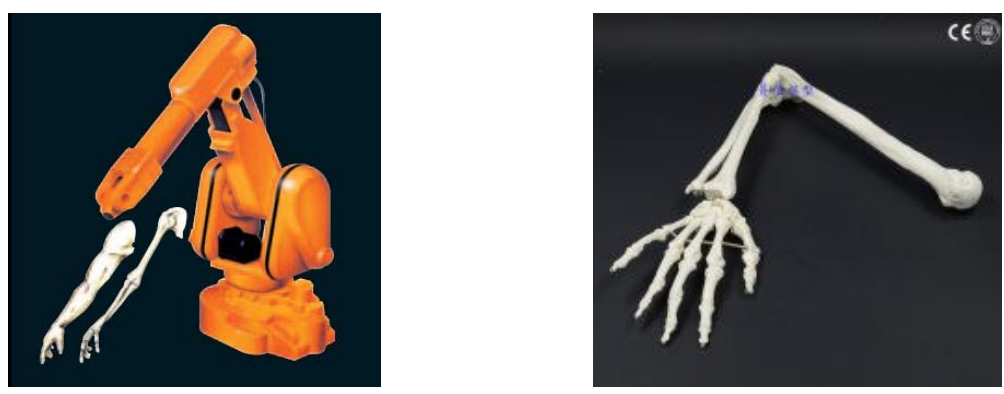

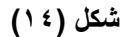

تصميم جهاز رفع صناعي مستمدة ديناميكية حركته من ميكانيكا حركة اليد والذراع الطبيعية

https://en.wikipedia.org/wiki/Industrial_robot المصدري

https://www.aliexpress.com/price/human-arm-model_price.html

1 - 1 دراسة تحليلية للنموذج التصميمي الحادي عشر:

يلاحظ من خلال الدر اسة التحليلية للنموذج التصميمي الحادي عشر الموضح بشكلي ( (1) ع () استلهام المصدم الصناعي فكرة وديناميكية حركة تصميم البد الصناعية ، و الحفــار، و الرو افع الصناعية من شكل وديناميكية حركة الذراع و اليد الطبيعية للإنســان ، وارتبــاط

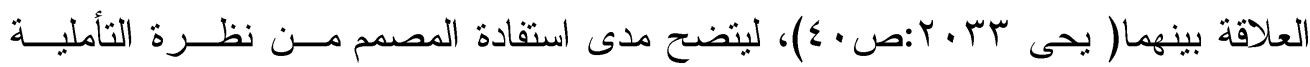




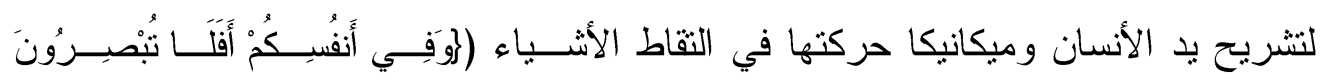

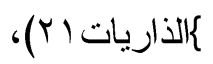

إضافة لكل بما يحبط به من كائنات من حيو انات وطيور وخاصة سلوكها وميكانيكا حركتها

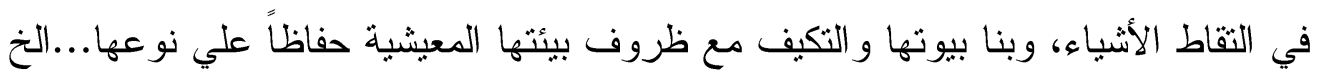

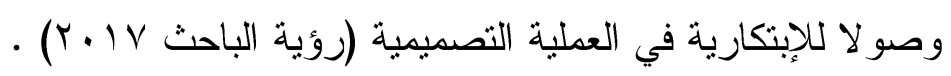

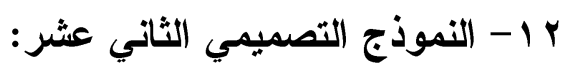

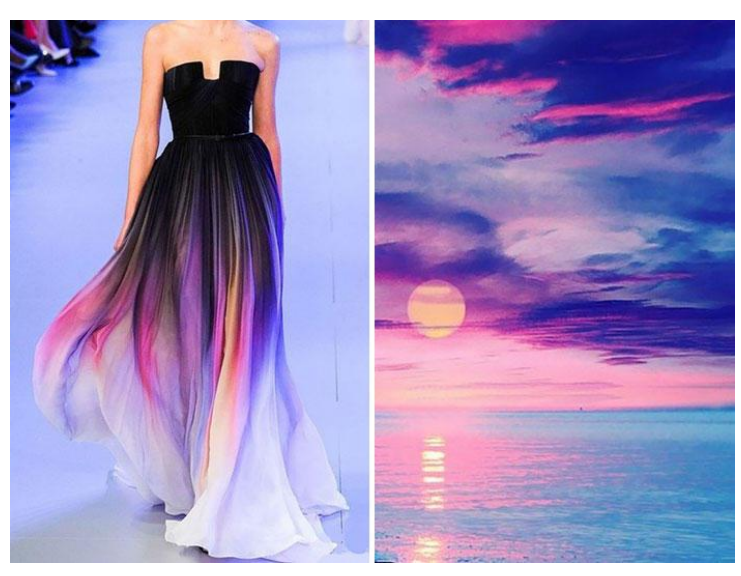

شكل (10)

تصميم زى نسائي مستوحى من الطبيعة و ألو انها الجذابة

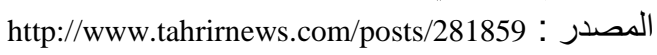

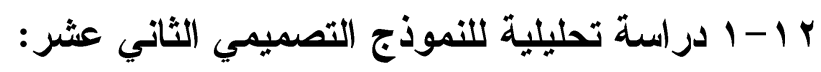

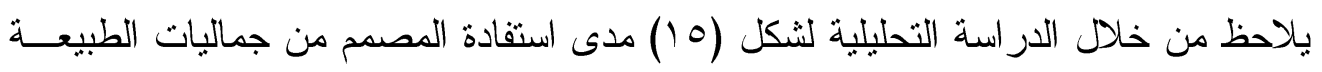

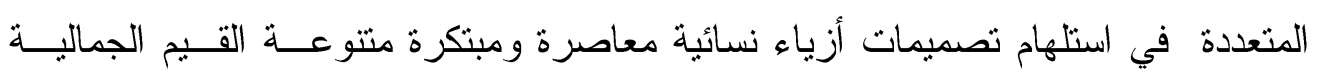

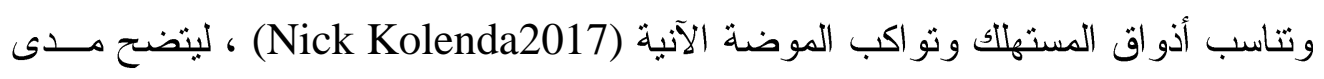

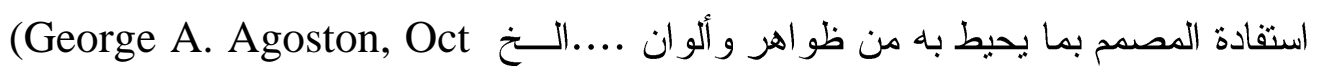

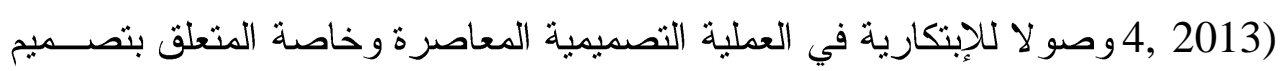

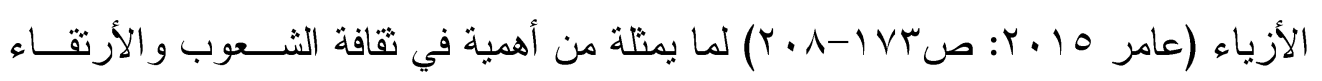

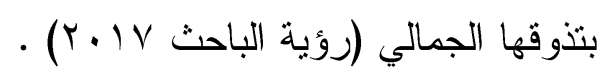




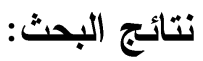

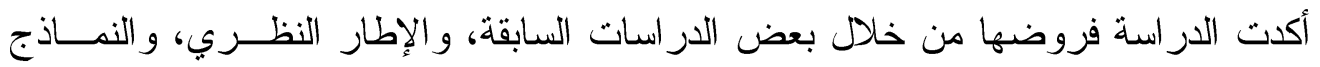

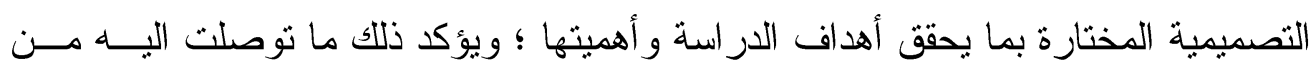

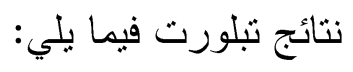

1- تنمية القدر ات الثأملية للمصم يؤثر إيجابياً في زيادة قدر اته الإدر اكية و الإبتكارية .

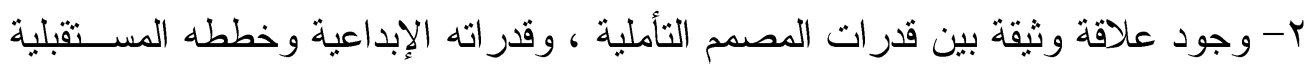

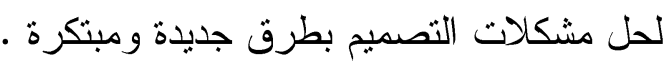

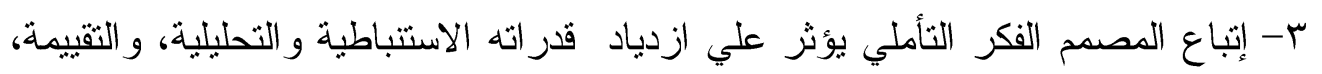
و الثتويمة لأعماله أثناء العملية الإبداعية بمر احلها المختلفة.

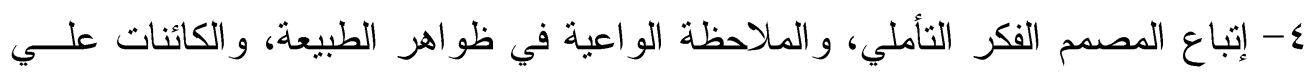
اختلاف أنو اعها، وكذا كل ما يحيط به من حر الك يومي يساعده فـــي اســتنباط، واختيــار

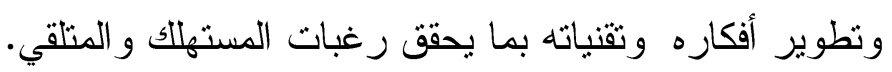
0- الفكري الثأملي من أهم العوامل المعرفية، والمعلوماتية في عمليات التذوق و التفضـيليل

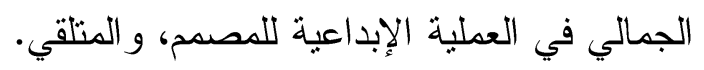
V- التأمل و الملاحظة من أهم العو امل في العمليات و التثنيات الإبداعية و الابتكارية للمصمم

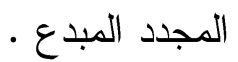

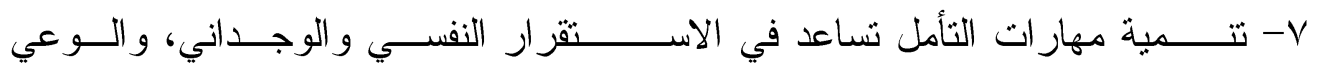

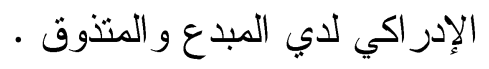




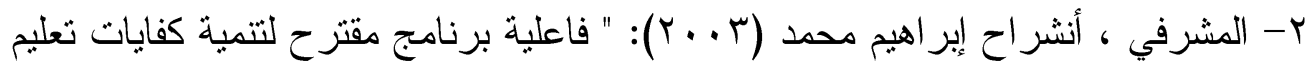

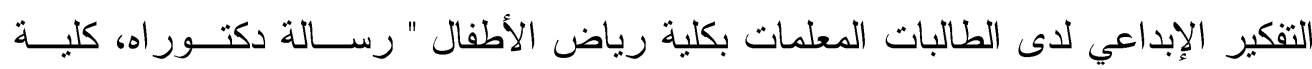

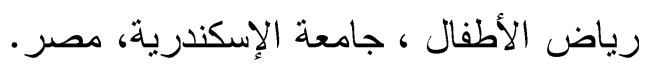

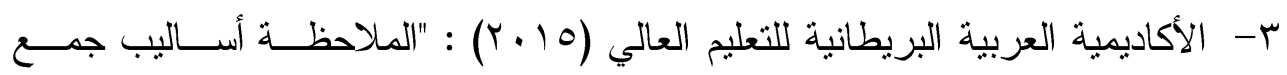
و وعرض المعلومات" Www.abahe.co.uk

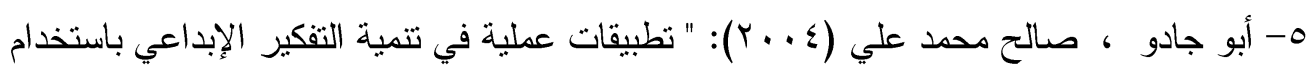

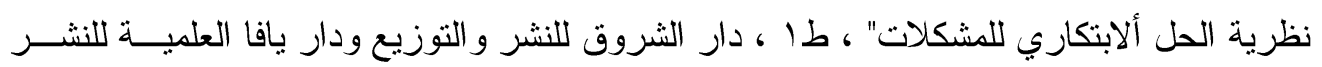
و النوزيع و الطباعة ، عمان.

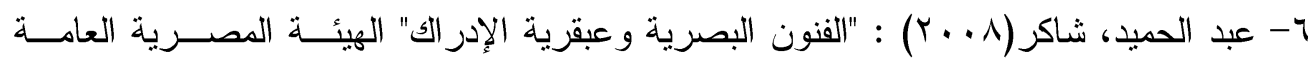

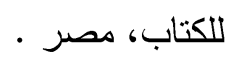
V- عبد الحميد، شاكر(1999) : " التفضيل الجمالي دراسة في سيكولوجية التذوق الفني" ، عـالم ، الكير

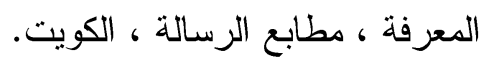

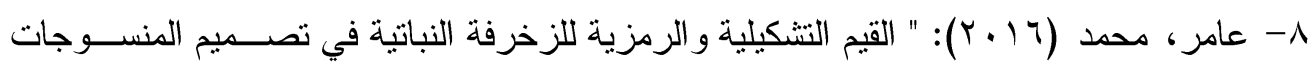

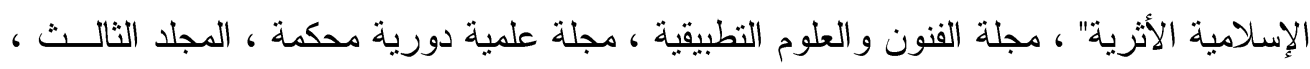

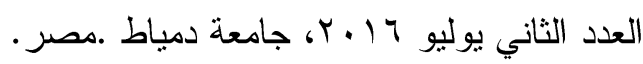

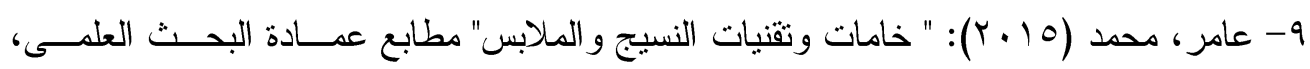

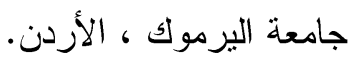

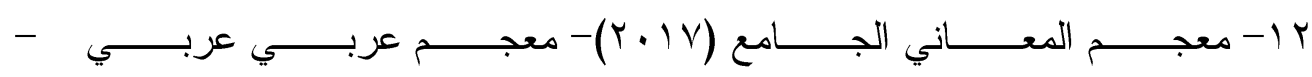
(www.almaany.com/ar/dict/ar-ar)

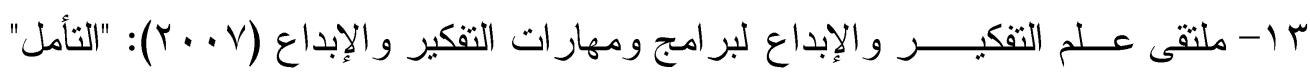
.http://www.memar.net

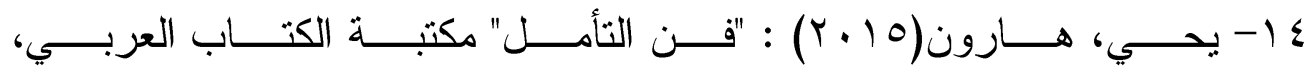
.www.arabbook.com

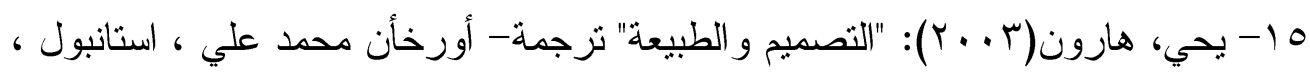
تزكيا. 
16- Autodesk Design Academy(2008); "Design Basics), Inc .

17- Akaydin M.( 2009); "Characteristics of fabrics knitted with basic knitting structures from combed ring and compact yarns" Indian $\mathbf{J}$ Fibre Text Res;34:26-30.

18- Buesgen, A.,( 2015); "Shell Three-dimensional Woven Textiles, Advances in 3D Textiles", Elsevier Ltd, p.79-96.

19- Dilwar Hussain\&nd Braj Bhushan (2010) :" Psychology of Meditation and Health: Present Status and Future Directions", International Journal of Psychology and Psychological Therapy.

20- Daphne M. Davis and Jeffrey A. Hayes,(2011): " PRACTICE REVIEW What Are the Benefits of Mindfulness? A Practice Review of Psychotherapy-Related Research" 2011 American Psychological Associat, , Vol. 48, No. 2, 198 -208.

21- George A. Agoston, (Oct 4, 2013) ; "Color Theory and Its Application in Art and Design (Springer Series in Optical Sciences)" . 22- Hodgins, H. S., \& Adair, K. C. (2010); "Attentional processes and meditation.Consciousness and Cognition" 19(4), 872-878

23- http://www.saaid.net/Doat/khabab/62.htm

24- http://www.alukah.net/social/0/34490/\#ixzz313OYourH

25- http://www.islam-qa.com

26- http://muntada.islamtoday.net

27- http://almoslim.net

28- Lorenza S. Colzato\& Armin Kibele (2017) : " How Different Types of Meditation Can Enhance Athletic Performance Depending on the 
Specific Sport Skills", J Cogn Enhanc, This article is an open access publication .

29- Lois Fichner-Rathus,(Feb 13, 2007) ; " Foundations of Art and Design (with Art Experience Online Printed Access Card)"

30- Mostafa El Gamal, Mohamed. M .Amer (2016) : " DEVELOPING NEW TREND IN HONEYCOMB WOVEN METHOD TO BENEFIT IT IN CREATIVE DESIGN FOR DECORATIVE CURTAINS USING DOUBLE FACE FABRICS" The 4th International Conference, Fculty of Applied Arts, Helwan University. 31- Nick Kolenda,(2015) ; "Methods of Persuasion: How to Use Psychology to Influence Human Behavior" Kindle Edition .

32- National Council for Curriculum and Assessment 2017

33- Una Halligan Chairperson(2009),"Skills in Creativity, Design and Innovation " Expert Group on Future Skills Needs, Forfas.

34- V. V. Sushkov, N. J. I. Mars \& P. M. Wognum(1995), "Introduction to TIPS: a theory for creative design" Elsevier sciences limited, Printed in Great Britain.

35- Walter.W., Mills. Md., \& John. T. Farrow (1981)," The Transcendental Meditation Technique and Acute Experimental Pain" by the American Psychosomatic Society, Inc Published by Elsevier North Holland, Inc 52 Vandcrbilt Ave, New York, NY 10017 